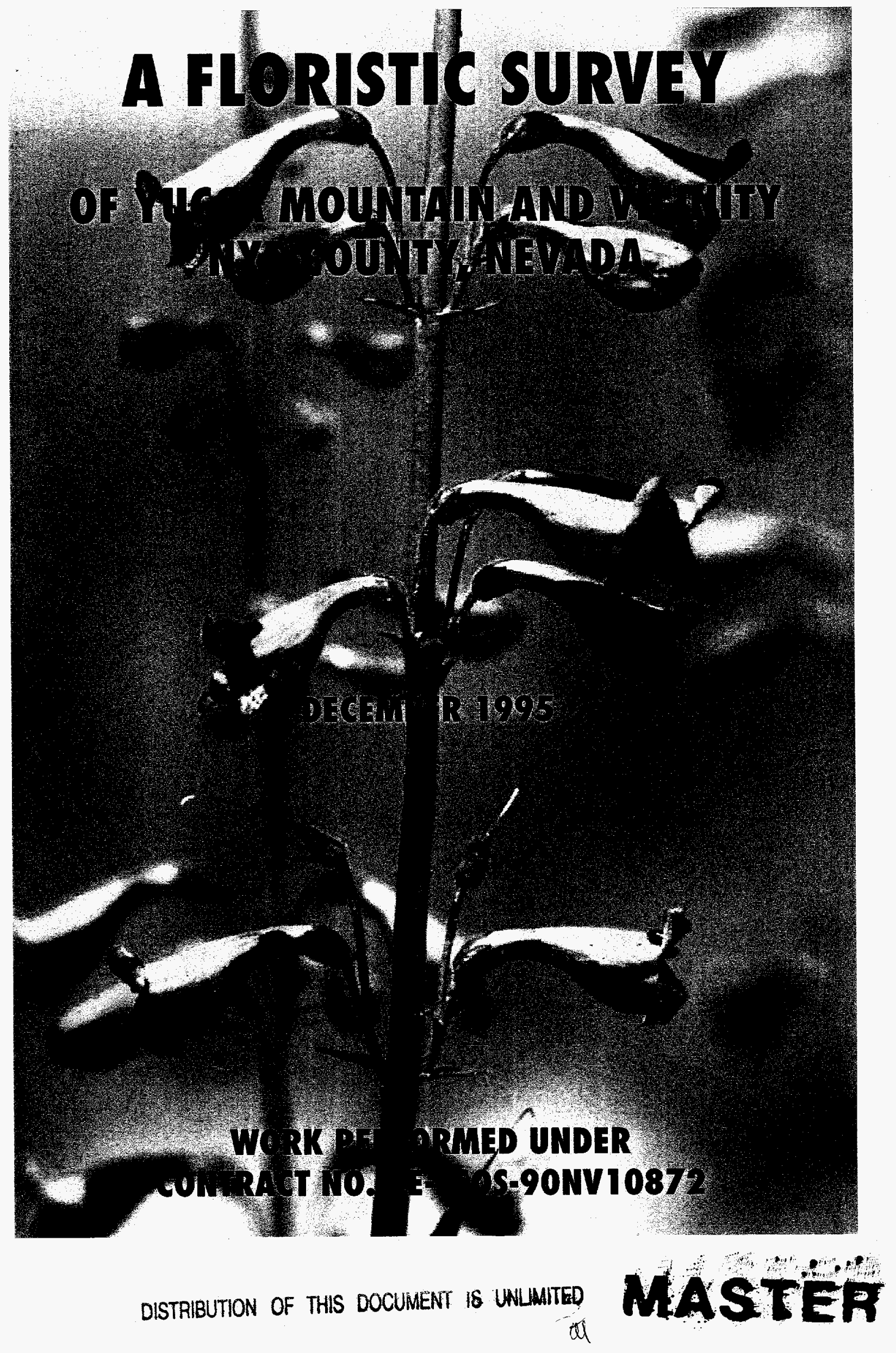




\section{A FLORISTIC SURVEY OF YUCCA MOUNTAIN AND VICINITY NYE COUNTY, NEVADA}

by

Wesley E. Niles

Patrick J. Leary

James S. Holland

Fred H. Landau

December, 1995

Prepared for U. S. Department of Energy, Nevada Operations Office under Contract No. DE/NV DE-FCO8-90NV10872

This report was prepared as an account of work sponsored by an agency of the United States Government. Neither the United States Government nor any agency thereof, nor any of their employees, makes any warranty, express or implied, or assumes any legal liability or responsibility for the accuracy, completeness, or usefulness of any information, apparatus, product, or process disclosed, or represents that its use would not infringe privately owned rights. Reference herein to any specific commercial product, process, or service by trade name, trademark, manufacturer, or otherwise does not necessarily constitute or imply its endorsement, recommendation, or favoring by the United States Government or any agency thereof. The views and opinions of authors expressed herein do not necessarily state or reflect those of the United States Government or any agency thereof. 


\section{DISCLAMMER}

Portions of this document may be illegible in electronic image products. Images are produced from the best available original document. 


\section{ABSTRACT}

A survey of the vascular flora of Yucca Mountain and vicinity, Nye County, Nevada, was conducted from March to June 1994, and from March to October 1995. An annotated checklist of recorded taxa was compiled. Voucher plant specimens were collected and accessioned into the Herbarium at the University of Nevada, Las Vegas. Collection data accompanying these specimens were entered into that herbarium's electronic data base. Combined results from this survey and the works of other investigators reveal the presence of a total of 375 specific and intraspecific taxa within the area, these allocated to 179 genera and 54 families. .

No taxon currently listed as threatened or endangered under the Endangered Species Act was encountered during this study. Several candidate species for listing under this Act were present, and distributional data for these were recorded. No change in the status of these candidate species is recommended as the result of this study. 


\section{ACKNOWLEDGEMENTS}

This study has been conducted under contract with the $U$. $S$. Department of Energy (DOE Contract Number DE-FC08-90NV10872), and funded through a cooperative agreement between the Yucca Mountain Site Characterization Project Office (NV-YMSCPO) and the University of Nevada, Las Vegas (UNLV).

The investigators express their appreciation to NV-YMSCPO personnel for their support and assistance, and to UNLV's offices of Associate Vice President for Research and Director of Research Administration. Jason A. Alexander provided assistance during the preparation of this report. 
ABSTRACT ii

ACKNOWLEDGEMENTS $\ldots \ldots \ldots \ldots \ldots \ldots \ldots \ldots \ldots \ldots \ldots \ldots \ldots \ldots \ldots \ldots \ldots$ iii

LIST OF FIGURES $\ldots \ldots \ldots \ldots \ldots \ldots \ldots \ldots \ldots \ldots \ldots \ldots \ldots \ldots \ldots \ldots \ldots \ldots$

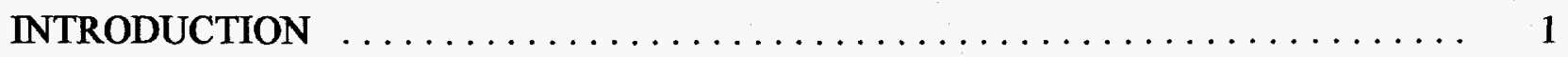

MATERIALS AND METHODS $\ldots \ldots \ldots \ldots \ldots \ldots \ldots \ldots \ldots \ldots \ldots \ldots \ldots \ldots$

STUDY AREA BOUNDARIES $\ldots \ldots \ldots \ldots \ldots \ldots \ldots \ldots \ldots \ldots \ldots \ldots \ldots \ldots \ldots \ldots$

GEOLOGY .................................. 4

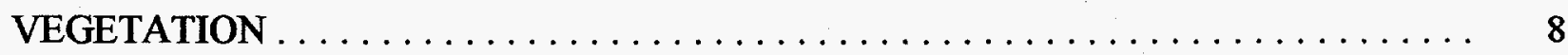

THREATENED/ENDANGERED SPECIES $\ldots \ldots \ldots \ldots \ldots \ldots \ldots \ldots \ldots \ldots, 12$

RESULTS . . . . . . . . . . . . . . . . . . . .

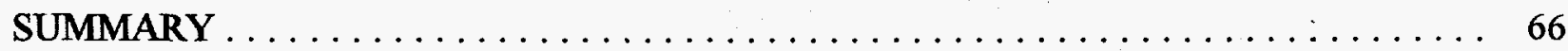

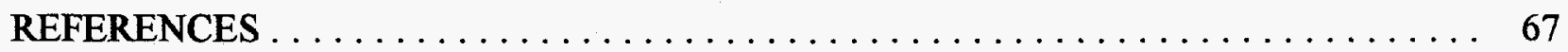




\section{LIST OF FIGURES}

Figure

Page

1 View eastward from Bare Mountain. . . . . . . . . . . . . . . . . 3

2 View westward from near the base of Yucca Mountain .............. 7

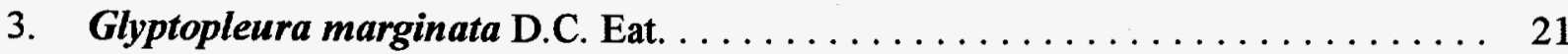

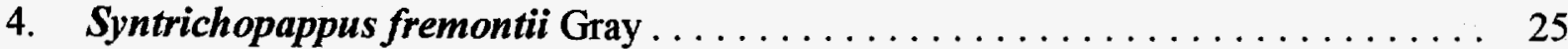

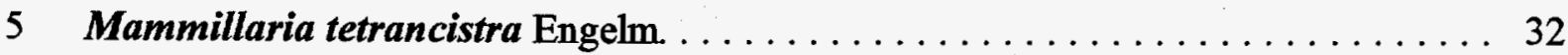

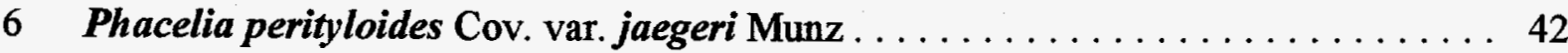

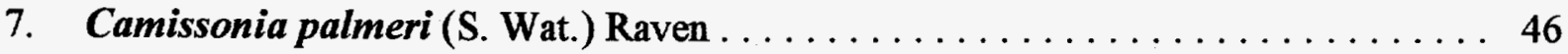

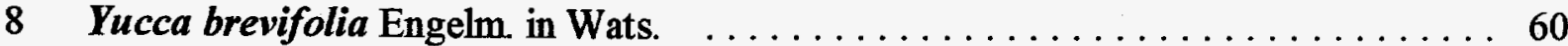

Cover:

Penstemon floridus Bdg. var. austinii (Eastw.) N. Holmgren. Local populations of this perennial herb occur in the gravels of Forty-Mile Wash (Nevada Test Site), Chuckwalla Canyon (Bare Mountain), Beatty Wash, and occasionally at other sites within the study area. 


\section{INTRODUCTION}

Yucca Mountain, located, in part, along the southwestern boundary of the U.S. Department of Energy's Nevada 'Test Site, Nye County, Nevada, is under consideration as a possible location for a national high-level radioactive waste repository. The present study, part of the over-all site characterization process initiated in 1978, supplements previously completed biotic studies and provides site-specific information on the flora of southern Yucca Mountain and contiguous areas.

This floristic survey was conducted from March to June 1994 and from March to October 1995, and covered an area of approximately 150 square miles.

Vegetation of the Yucca Mountain characterization site has been analyzed and described by Collins and O'Farrell (1985) and by O'Farrell and Collins (1983, 1984); and that of the Nevada Test Site by Beatley (1976). Other publications relating to the vegetation and flora of southern Yucca Mountain and vicinity are Iisted in the REFERENCES section of this report.

Plant lists compiled during this survey provide for a more complete knowledge of the plant resources to be found in the area. Plant specimens collected as part of this study have been accessioned into the Herbarium of the University of Nevada, Las Vegas.

\section{MATERIALS AND METHODS}

The flora of the southern Yucca Mountain project area was surveyed on foot between March lst and June 30th, 1994, and from March Ist to October 31st, 1995, by four professional botanists.

Comprehensive plant lists were compiled at one-quarter mile intervals along Yucca Mountain ridge, with personnel walking the east-west width of the crest and adjacent slopes. Similar surveys were conducted elsewhere at selected sites throughout the area; site selection was often dictated by factors of accessibility and anticipated botanical diversity.

The 1994 portion of this survey followed winter months (November 1993 to February 1994) during which precipitation was essentially 
nil, so that the season's study was necessarily restricted primarily to those plants of a perennial growth habit. However, ample late winter precipitation preceded the 1995 field season. This led to a reasonably abundant display of winter annuals, and permitted an inventory of those taxa that had been absent from the area during the previous year.

Plant lists compiled in each area by botanical teams were combined to provide a checklist for that area. In those instances where field plant identification was not possible, specimens were collected for later determination and for addition to the master checklist. Collections were made of plants in flower or fruiting condition, and these have been accessioned into the Herbarium at the University of Nevada, Las Vegas. Collection data accompanying the specimens have been inserted into the expanding botanical data base being developed.

Plant species of special concern, e.g., those designated as threatened or endangered, or otherwise rare, or of special scientific interest were noted, along with appropriate information regarding occurrence and distribution within the study area. Photographic documentation of these occurrences was made.

A master list of plants surveyed was compiled, as were lists of previously unreported taxa, and those of special concern (see the RESULTS section of this report).

\section{STUDY AREA BOUNDARIES}

This floristic study was conducted over approximately 150 square miles. It included the nearly 28 square mile characterization site atop Yucca Mountain; the lower elevation ridges, bajadas, and drainages south of Calico Hills and west of Forty-mile Wash; that northern portion adjacent to the U.S. Air Force Nellis Bombing Range; Bureau of Land Management areas to the north and west (Solitario Canyon, Crater Flat, the eastern slope and canyons of Bare Mountain, Tate and Beatty Washes); and that region south to U.S. highway 93, Steves Pass and Black Marble Mountain. 


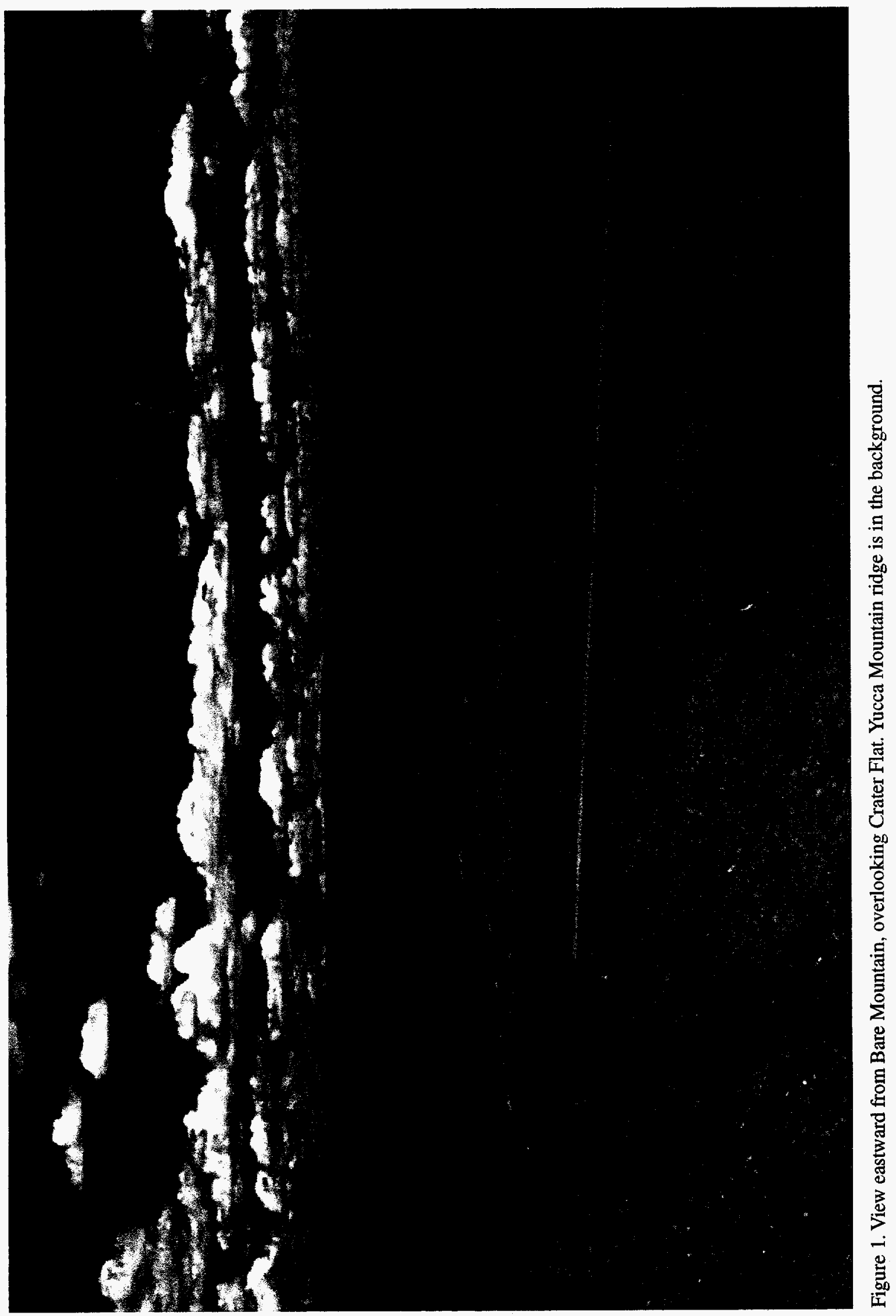


The study area encompasses geology that varies from recent alluvial deposits, to Quaternary and Tertiary volcanics, and Mesozoic and Paleozoic sedimentary and metamorphic rocks. The variety of parent rock substrates and derived soils provides a wealth of ecological opportunities for the many and diverse plant species of the area. The following geologic account has been abstracted from cornwall (1972).

Bare Mountain is a predominantly limestone-dolomite mountain, oriented in a north-south direction. Several west to east canyons dissect the mountain mass. The high ridges and spurs are commonly sharp and the walls of the canyons are characteristically steep. Bare Mountain is geologically quite complex. The geological complexity has created various mining opportunities. Fluorspar is mined in portions of the Bare Mountain area. In addition, gold, silver, and mercury, as well as volcanic cinders and pumicite, have been extracted from the region.

The geology of the area is described here by geography, detailing the southern section first, then examining the central and finally, the more northerly portions last. older rock formations tend to outcrop at the southern portion of Bare Mountain, while more recent rocks are exposed in the northern section, so the discussion is also organized in an oldest to youngest rock order.

Steves Pass (elevation 2,951 feet), is located at the southern boundary of the study area. Three components of the Johnnie (?) formation make up this southern portion of Bare Mountain. The Johnnie (?) formation is of lower Cambrian age and is the oldest and thickest formation in the region, up to 4,800 feet thick. It consists of minor carbonate rock, dolomite and limestone that becomes sandy upward, and a large amount of quartzitic sandstone, silty sandstone, and siltstone. The remainder of the formation is micaceous shale and conglomerate interstratified in zones. The components of the Johnnie (?) formation have commonly undergone low grade metamorphosis to form phyllite, schist, quartzite, and marble. Two prominent quartzite units, each approximately 300 feet thick, occur near the middle and top of the formation.

Wildcat Peak (elevation 5,047 feet, Bare Mountain) is comprised mainly of the stirling quartzite. This lower Cambrian quartzite 
appears pale red from a distance. An outcrop of the Carrara formation occurs on the ridge east of the peak. This lower Cambrian formation consists of siltstone, quartzite, and sandstone. The lower portion is composed of alternating quartzite, sandstone, siltstone, phyllitic shale, and minor limestone alternating with shale and siltstone. A middle portion is composed of limestone alternating with shale and siltstone. The upper component is a fine-grained limestone which is marblized in places. The first major canyon to the north of Wildcat Peak is mostly of the Bonanza King formation, a middle to late Cambrian, fine-grained, banded dolomite. Parts of this formation contains intercalated silty and sandy layers and some cherty zones. This is the canyon in which Gilia ripleyi was located.

We did not sample that region of Bare Mountain between the canyon north of Wildcat Peak and Chuckawalla Canyon because of large scale and active mining operations. This complex portion of the mountain consists of the upper Cambrian Nopah formation, the Johnnie(?) formation, the Carrara formation, the stirling quartzite, the Bonanza King formation, the upper ordovician Ely Springs dolomite, the lower Ordovician Pogonip group, the middle Silurian Roberts Mountains formation, the Lone Mountain dolomite, and Tertiary and Quaternary porphyry intrusions or flows.

Chuckawalla Canyon, Bare Mountain, has several formations outcropped on its southern ridge. The lower Ordovician Pogonip group is a primarily carbonate formation. The lowest portion is a silty, cherty limestone with cherty dolomite at the base. The uppermost part is shaly limestone interbedded with pure limestone, and grades through a very thin sandy zone into the overlying Eureka quartzite. The middle Ordovician Eureka quartzite typically outcrops as a cliff with thin sandstone units at the bottom and top. The upper Ordovician Ely springs dolomite is a fine-grained dolomite with anastomosing lenses of chert. Quartzitic sandstone occurs at the base. The middle silurian Roberts Mountains formation is a sandy and cherty dolomite at the base, platy limestone and limey dolomite in the middle section, and is dolomite in the upper portion. The upper Silurian Lone Mountain dolomite outcrops here. This is a relatively homogeneous dolomite. VABM Bare Mountain, elevation 6,316 feet, is comprised primarily of Ely Springs dolomite and Eureka quartzite, with some Roberts Mountains formation outcropping on the north side. The northern ridge of Chuckawalla Canyon is Roberts Mountains formation, Lone Mountain 
dolomite, and Ely Springs dolomite.

Tarantula Canyon, Bare Mountain, has an accumulation of Quaternary alluvium in a large, open basin. The southern ridge at the mouth of the canyon has some middle Devonian Fluorspar Canyon formation, while the majority is Lone Mountain dolomite. The Fluorspar Canyon formation exposed here is a cherty dolomite with lenses of sandstone and dolomite, and a little limestone. The head of this canyon, known as Razorback, has the following formations outcropped, in order from south to north: Eureka quartzite, Pogonip group, and Nopah formation. The late Cambrian Nopah formation consists of a thin basal shale and a thick upper dolomite. The northern ridge consists of the upper Mississippian Meiklejohn formation and stirling quartzite. The Meiklejohn formation is quite diverse in composition, consisting of siltstone, claystone and shale, with lesser amounts of sandstone, conglomerate, and limestone.

The area at Specie Spring, Bare Mountain, is dominated by the Carrara formation.

Secret Pass, elevation 4,966, Bare Mountain, is a continuation of the Meiklejohn formation.

Meiklejohn Peak, Bare Mountain, is comprised of the Pogonip group, Eureka quartzite, Ely Springs dolomite, Roberts Mountains formation, Lone Mountain dolomite, Fluorspar Canyon formation, and Tertiary and Quaternary tuff. The Cenozoic age tuff contains broken crystals and small fragments of pumice, stony rhyolite, and rhyolitic glass in a pumiceous matrix. Most of the tuff is moderately to well lithified, but parts of the youngest tuff are loosely consolidated. The northern boundary of Bare Mountain, with respect to this study, occurs at Tates Wash and Joshua Hollow, areas of alluvial accumulation.

The Beatty Wash area that was studied consisted of widespread amounts of Tertiary and Quaternary tuff and welded tuff. The welded rhyolitic tuff is predominately stony. Interspersed are smaller amounts of Tertiary and Quaternary porphyry intrusions or flows, some of which are glassy. Quaternary alluvium accumulates in the bottom of Beatty Wash throughout its length. 


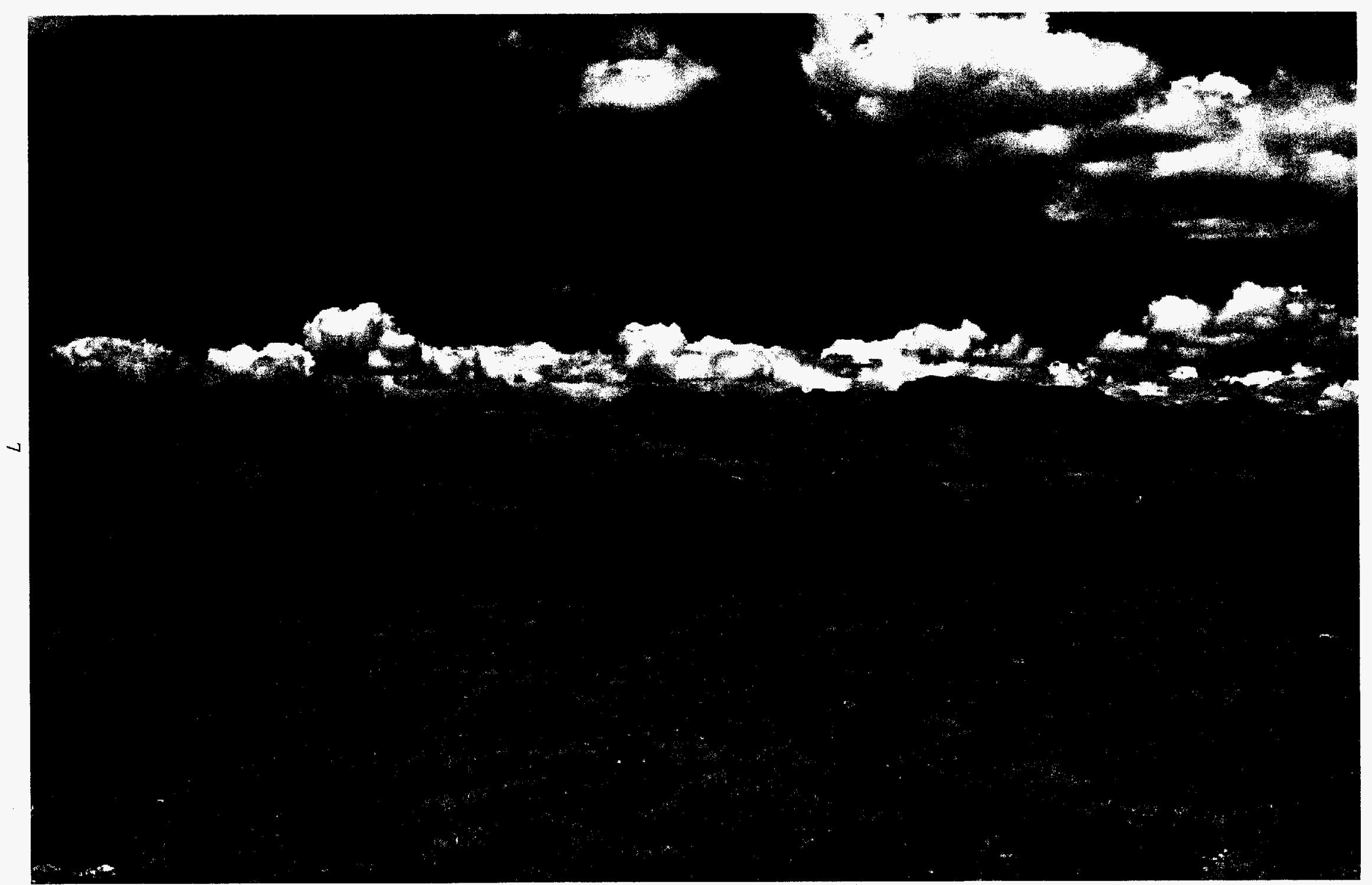

Figure 2. View westward from near the base of Yucca Mountain, showing the mixed shrub vegetation of Crater Flat (Larrea tridentata, Lycium andersonii, and Grayia spinosa dominants). Bare Mountain is in the background. 
Crater Flat is a vast, relatively flat expanse that drains generally southward. Quaternary alluvium makes up over $90 \%$ of this area, but it is disrupted by the basalt found at the Black, Red, and Little Cones, and at a few other locations. This material is derived from porphyritic basalt flows, dikes, and cinder cones. The cinder cones in the crater Flat area are distinctive volcanic features that are Quaternary in age and that have not been appreciably modified by erosion since their formation.

Yucca Mountain is a volcanic mass in the form of a mesa. It is made up of mostly welded tuff. Fairly large amounts of tuff also outcrop. Northern Yucca Mountain has small outcrops of porphyry intrusions or flows, some of which are glassy. The same Tertiary volcanics make up Busted Butte. This area is not nearly as severely faulted as the Bare Mountain portion of the study area.

Fortymile Wash, which forms the eastern boundary of the study area, consists of Quaternary alluvium.

The geological structural history of the Bare Mountain-Yucca Mountain area is complex and of long duration. The principal deformations were folding in the mid to late Paleozoic, intense thrust faulting and lateral faulting in the Mesozoic, moderate thrust and normal faulting in the mid to late Tertiary and, finally, normal faulting from the late Tertiary to Recent.

\section{VEGETATION}

Vegetation of the nearly 28 square mile characterization site atop Yucca Mountain has been both qualitatively and quantitatively described in several publications (O'Farrell and Collins, 1983, 1984; Collins and O'Farrel1, 1985), and that of the Nevada Test Site by Beatley (1976). These studies serve as the basis for the present discussion.

In Beatley's analysis, plant communities were initially divided by physiographic province: Mojave Desert and Great Basin Desert. The Yucca Mountain area, as represented in the southwestern portion of the Nevada Test Site, contains primarily Mojave Desert plant communities. 
The Mojave Desert vegetation is described using physiographic features. These include bajadas, mountains, arroyos (washes), and springs and seeps. Other plant communities of the Nevada Test Site are classified as transitional between the two North American Deserts.

Bajadas. Creosote-bush (Larrea tridentata) is a dominant shrub of the bajadas or gentle slopes forming benches above the valley floors, extending to the base of the steeper mountain slopes. These are generally below 4,000 feet in elevation. The bajadas support mosaics of communities with various codominants and associated species. Creosote-bush's dominant status is usually based on its size. Its canopy nearly always occupies the upper layer of the two-layered shrub communities, although it may occur in low numbers and with low percentage cover in relation to other shrub species.

Over most of the study area, Ambrosia dumosa (bur-sage), Lycium andersonii (desert-thorn), Grayia spinosa (hop-sage), and Atriplex confertifolia (shadscale) are the usual codominants, and their degree of representation in the communities appears to be under the major controls of climate and/or physical properties of the soils.

Where soils are deep, loose sands without a surface pavement, a plant association in which Larrea and Ambrosia dumosa are the dominants reaches its best development. Other associates in this community are Lycium shockleyi (Shockley's desert-thorn), Ephedra torreyana (Mormon-tea), and stipa hymenoides (Indian ricegrass). In the project area, this prevailing vegetation exists along the southern edge in the northern Amargosa Valley, extending north to Yucca Mountain and west to Steves Pass, through the southern Crater Flat area.

Communities of higher elevations $(3,500$ to 4,000 feet) and rocky soils with a surface pavement and without a hardpan near the surface usually have as their dominants Larrea, Lycium andersonii, (Anderson's desert-thorn), and Grayia spinosa. In these areas Ambrosia dumosa distribution varies and Haplopappus cooperi (goldenweed) may increase to become a conspicuous element of the community. Yucca brevifolia (Joshua-tree) is sporadic within this community and is conspicuous where it does occur. 
Within the study area this community is widespread, forming the major component of the low elevation vegetation above the LarreaAmbrosia community. It is represented along the base of Bare and Yucca Mountains, northern Crater Flat, and the shoulders of Beatty Wash.

On the bajadas, as described by Beatley, communities in which Larrea and Atriplex confertifolia are consistent dominants cover a major portion of the Mojave area. This is related to the calcareous soil materials originating in the limestone-dolomite mountain ranges and foothills. Here the surface pavement is usually well developed, and the soil matrix is generally finetextured; there is also a hardpan layer (caliche) near the surface.

These bajada communities are regionally those with the greatest floristic diversity. In most communities, Psorothamnus fremontii (indigo-bush), Eriogonum fasciculatum (buckwheat), and Krameria parvifolia (range ratany) are prominently represented. In certain ones a Mormon-tea is present (Ephedra nevadensis or Ephedra funerea), both of which have highly restricted and only slightly overlapping distributions. Yucca schidigera (Mojave yucca) occurs within this community. Opuntia ramosissima (pencil cactus) is only reported. Opuntia basilaris (beavertail cactus), the most widely distributed cactus in the region, is frequent in these areas.

Mountains. The Yucca and Bare Mountain areas are very diverse geologically, but generally support similar plant communities. The mountains, as described by Beatley, in the Mojave region extend up to an elevation of 6,000 feet. The mountains in this area are extremely rugged, with active, steep slopes often composed of loose talus material. In these steep areas, perennial plants have not been able to become established, resulting in large areas barren of perennial vegetation.

A large total number of species are known from these mountains, but the one that occurs throughout the mountainous area is Atriplex confertifolia. The vegetation has therefore been classified as Atriplex because this is the unifying, if often inconspicuous, species of the limestone-dolomite ranges, and not because it is necessarily the common shrub present. Most of the species listed previously for the Larrea-Atriplex communities of the bajadas below these ranges also occur in the mountains above. 
There is a noticeable increase in the herbaceous component of the vegetation in the mountainous areas. Plant diversity and perennial grass cover increase on the mountain slopes. This may simply be an indicator of reduced burro and domestic livestock activity in these areas.

Arroyos. Plants of the arroyos (washes) are generally those found on the surrounding bajadas, but there are also those which are restricted to these environments. Dry mountain canyons and desert washes characterize this habitat. Two rabbitbrushes (chrysothamnus paniculatus and Chrysothamnus nauseosus), and Atriplex polycarpa (saltbush) are common in many drainages. Also, Ambrosia eriocentra (woolly bursage), Salazaria mexicana (bladder-sage), Fallugia paradoxa (Apache-plume), and Prunus fasciculata (desert-almond) occur in these areas. Tamarix ramosissima (salt-cedar) is well established in Fortymile Wash and Beatty Wash and many of the other smaller drainages.

Springs and seeps. Most of Beatley's analysis of the riparian communities is based on the Ash Meadows area of Nevada located to the south, but two spring/seep locations were included in the study area. Specie Spring, located in Tarantula Canyon, supports Salix lasiolepis (arroyo willow), Baccharis emoryi (seepwillow), Forestiera neomexicana (desert-olive), Rhus trilobata (squawbush), and Brickellia microphylla (little leaf brickell-bush). Two small ponds, representing overflow from a drilled, active well in Fortymile Wash have, at their edges, Tamarix ramosissima (saltcedar), Typha latifolia (cat-tail), and a sedge (Carex praegracilis).

\section{THREATENED/ENDANGERED SPECIES}

There are a number of plants occurring in the study area that are candidates for listing under the Endangered species Act. However, no plants currently listed as threatened or endangered were located in the area. Candidate plants include: Lathyrus hitchcockianus (Hitchcock's pea), the cactus Sclerocactus polyancistris, and Gilia ripleyi (Ripley's gilia).

The distribution and status of these candidate species was illustrated by Beatley (1977), Rhoads and Williams (1977), and by 
Rhoads, Cochrane and Williams (1978, 1979). These works contain detailed discussion on the biology of these species and are not restated here.

Additional locations for some of these candidate species are recorded in the checklist portion of this report. Based on this study, no change is recommended in the status of these species under the Endangered Species Act. 


\section{RESULTS \\ ANNOTATED CHECKLIST OF THE \\ VASCULAR PLANTS OF YUCCA YOUNTAIN AND VICINITY}

In the checklist that follows, families are arranged in alphabetical order under the major subdivisions, as are also the genera and species within each family. Nomenclature follows Kartesz (1994), Welsh et al. (1993), Hickman (1993) and Flora of North America Editorial Committee (1993). Common names are provided where available.

Three primary sources of information were used in compiling the checklist. These include: Beatley (1977), Collins and O'Farrell (1985), O'Farrell and Collins (1983), O'Farrell and Collins, (1984), and fieldwork conducted as part of this project. These sources are represented in this checklist by. JCB, O\&C and UNLV, respectively.

Plant occurrences are recorded by location. Both observations and collections are included. Collections made as part of this study are indicated by "UNLV-C" and are deposited in the UNLV Herbarium. Noteworthy collections representing taxa not previously reported from the area are indicated by this symbol, $>$.

\section{Division POLYPODIOPHYTA Ferns \\ Pteridaceae Maidenhair Fern Family}

Argyrochosma

Arcyrochosma jonesii (Maxon) M.D. Windham Jones' cloak-fern

[ Notholaena jonesii Maxon;

Cheilanthes ionesii (Maxon) Munz]

Meiklejohn Mtn. (UNLV-C) .

Cheilanthes

Cheilanthes covillei Maxon

Coville's lipfern

Chuckwalla Canyon (UNLV-C).

Cheilanthes feei T. Moore

Slender lipfern

Tarantula Canyon(UNLV-C), Razorback Ridge(UNLV-C) .

Cheilanthes parryi (D.C. Eat.] Domin

Parry's cloak-fern

[=Notholaena parryi. D. C. Eat.]

Bare Mtn. (UNLV, Black Marble Mtn. (UNLV), Chuckwalla Canyon(UNLV-C), Crescent Cliff(UNLV), canyon north of Wildcat Peak(UNLV-C).

Pellaea

Pellaea mucronata (D. C. Eat.) D. C. Eat. in Emory

Spiny cliff-brake

ssp. mucronata

Yucca Mtn. (JCB). 
Pellaea truncata Goodd.

Below Yucca Mtn. (JCB).

\title{
Pentagramma
}

Pentagrama triangularis (Kaulf.). Yatakievych, Windham \& E. Wollenweber ssp. triangularis

[=Pityrogramma triangularis (Kaulf.) Maxon Goldback fern

var. triangularis]

Specie Spring(UNLV-C), Crescent Cliff(UNLV), Beatty Wash(UNLV), Razorback Ridge (UNLV).

Division GNETOPHYTA Gnetophytes

Ephedraceae Mormon-tea or Joint-fir Family

\section{Ephedra}

\author{
Ephedra fasciculata \\ var. clokeyi (Cutler) Clokey \\ Crater Flat (UNLV-C).
}

Ephedra Eunerea Cov. \& Mort.

Death Valley ephedra

$[=$ E. californica

var. Eunerea (Cov.\& Mort.) L. Benson]

Steves Pass (UNLV), Black Marble Mtn. (UNLV-C), Crater Flat (UNLV), Tates Wash (UNLV), Busted Butte(UNLV), canyon north of Wildcat Peak (UNLV).

Ephedra nevadensis $S$. Wats.

Nevada ephedra

Crater Flat (UNLV-C), Chuckwalla Canyon(UNLV), Specie Spring(UNLV), Flourspar Canyon(UNLV), Tates Wash(UNLV), Crescent Cliff(UNLV), Tarantula Canyon(UNLV), Yucca Mtn. (O\&C, UNLV), Busted Butte(UNLV), Forty-Mile Wash(UNLV), Solitario Canyon(UNLV), canyon north of Wildcat Peak (UNLV), Beatty Wash(UNLV), Yucca Mtn. Ridge(UNLV), northeastern base of Yucca Mtn. (UNLV), Meiklejohn Mtn. (UNLV), Razorback Ridge (UNLV), Tates Wash (UNLV).

Ephedra viridis Cov.

Green ephedra Chuckwalla Canyon(UNLV), Specie Spring(UNLV), Fluorspar Canyon(UNLV), Tates Wash(UNLV), Crescent Cliff(UNLV), Tarantula Canyon(UNLV), Yucca Mtn. (O\&C, UNLV), Busted Butte(UNLV), Solitairo Canyon(UNLV), canyon north of Wildcat Peak (UNLV), Yucca Mtn. Ridge(UNLV), northeastern base of Yucca Mtn. (UNLV), Meiklejohn Mtn. (UNLV), Razorback Ridge(UNLV).

$$
\begin{aligned}
& \text { Division MAGNOLIOPHYTA Angiosperms } \\
& \text { Class MAGNOLIATAE Dicotyledons }
\end{aligned}
$$

Amaranthaceae Amaranth Family

\section{Amaranthus}

Amaranthus californicus (Moq.) S. Wats.

California amaranth [-Mengea californica Mog.] 
Forty-Mile Canyon Wash(JCB) .

Tidestromia

Tidestromia oblongifolia (S. Wats.) standl.

var. oblongifolia

[=Cladothrix oblongifolia Wats.]

Canyon north of Wildcat Peak (UNLV).

Anacardiaceae Sumac Family

Rhus

Rhus trilobata

skunkbush, squawbush

var. anisophylla (Greene) Jeps.

[=Rhus aromatica var. trilobata (Nutt.) Gray]

Specie Spring(UNLV-C) .

Apiaceae (Umbelliferae) Carrot Family

Lomatium

Lomatium nevadense (S. Wats.) Coult. \& Rose

Nevada lomatium

var. nevadensis

[=Peucedanum nevadense $S$. Wats.]

Crescent Cliff(UNLV-C), Tates Wash(UNLV-C), Yucca Mtn. (O\&C), Beatty Wash (UNLV-C), Yucca Mtn. Ridge (UNLV), Razorback Ridge(UNLV).

$D$ Lomatium parryi (s. Wats.) Macbr.

Parry's lomatium

[Peucedanum parryi $S$. Wats.]

Specie Spring(UNLV-C), Razorback Ridge(UNLV).

Asclepiadaceae Milkweed Family

Asclepias

Asclepias erosa Torr.

Desert milkweed

[=A. Leucophyl]a Engelm. in Parry]

Solitario Canyon(UNLV), Meiklejohn Mtn. (UNLV), Specie Spring(UNLV).

Asteraceae (Compositae) Sunflower Family

Acamptopappus

Acamptopappus shockleyi Gray

Steves Pass (UNLV), Crater Flat (UNLV), Chuckwalla Canyon(UNLV-C), Yucca Mtn. (O\&C), Busted Butte(UNLV), Forty-Mile Wash(UNLV), Beatty Wash (UNLV), Solitario Canyon(UNLV).

Ambrosia

Ambrosia acanthicarpa Hook.

Bur ragweed

[=Franseria acanthicarpa (Hook.) Cov.]

Amargosa Valley (JCB).

Ambrosia dumosa (Gray) Payne

Burro-weed, bursage

[=Eranseria dumosa Gray]

Crater Flat (UNLV), Steves Pass(UNLV), Black Marble Mtn. (UNLV), Crater Flat (UNLV), Tates Wash(UNLV), Chuckwalla Canyon(UNLV), Yucca 
Mtn. (O\&C, UNLV), Busted Butte(UNLV), Forty-Mile Wash(UNLV), Beatty Wash(UNLV), Solitario Canyon(UNLV), canyon north of Wildcat Peak(UNLV), southern base of Yucca Mtn. (UNLV), Tates Wash (UNLV).

Ambrosia eriocentra (Gray) Payne.

Wooly bursage

[=Franseria eriocentra Gray]

Forty-Mile Wash (UNLV), Beatty Wash(UNLV).

\section{Amphipappus}

Amphipappus Eremontii Torr. \& Gray

Chaff-bush Black Marble Mtn. (UNLV), Busted Butte(UNLV), canyon north of Wildcat Peak (UNLV), southern base of Yucca Mtn. (UNLV).

\section{Ani socoma}

Anisocoma acaulis Torr. \& Gray

Scale Bud

Forty-Mile Wash (UNLV-C).

\section{Artemisia}

Artemisia bigelovii Gray

Bigelow's sagebrush

Tarantula Canyon(UNLV), Chuckwalla Canyon(UNLV), Beatty Wash(UNLV)

Artemisia dracunculus L.

Tarragon

$[=\underline{A}$. aromatica A. Nels;

A. dranunculoides Pursh]

Specie Spring(UNLV-C), Crescent Cliff(UNLV), Meiklejohn Mtn. (UNLV).

Artemisia ludoviciana

ssp. incompta (Nutt.) Keck

[= . incompta (Nutt.) Keck]

Chuckwalla Canyon(UNLV), Specie Spring(UNLV), Crescent Cliff(UNLV), Tarantula Canyon(UNLV), Beatty Wash(UNLV), Solitario Canyon(UNLV), Yucca Mtn. Ridge(UNLV), northeastern base of Yucca Mtn. (UNLV), Meiklejohn Mtn. (UNLV), Razorback Ridge(UNLV), Tates Wash (UNLV-C).

Artemisia nova A. Nels

Black sagebrush

[=A. tridentata Nutt. ssp. nova (A. Nels.) H.\& C.

A. arbuscula Nutt. ssp. nova (A. Nels.) G. Ward]

Chuckwalla Canyon(UNLV), Razorback Ridge(UNLV).

Artemisia spinescens D. C. Eat.

Budsage

[= Picrothamnus desertorum Nutt.]

Fluorspar Canyon(UNLV), Tates Wash(UNLV-C), Yucca Mtn. (O\&C, UNLV), Busted Butte(UNLV), Beatty Wash(UNLV), Solitario Canyon(UNLV), Yucca Mtn. Ridge (UNLV) .

Artemisia tridentata Nutt.

Big sagebrush

var. tridentata

[=Serphidium tridentatum (Nutt.) W.A. Weber]

Fluorspar Canyon(UNLV), Tates Wash(UNLV), Chuckwalla Canyon(UNLV), Beatty Wash(UNLV), Razorback Ridge(UNLV), Tates Wash(UNLV-C). 
Baileya

Baileya pleniradiata Harv. \& Gray in Emory

Forty-Mile Wash(UNLV), Yucca Mtn. (O\&C).

Bebbia

Bebbia juncea (Benth.) Greene

Chuckwalla's delight, sweetbush [=Carphephorus juncea Benth.]

Yucca Mtn. (UNLV), canyon north of Wildcat Peak (UNLV-C).

\section{Brickellia}

Brickellia arguta Rob.

Busted Butte(JCB), canyon north of Wildcat Peak (UNLV).

Brickellia californica (Torr. \& Gray) Gray

California brickell-bush

[=Bulbostylis californica Torr. \& Gray

Coleosanthus californicus (Torr. \& Gray) Kuntze]

Busted Butte (UNLV).

Brickellia desertorum Cov.

Brickel1-bush

Bare Mtn. (JCB), Busted Butte (UNLV), canyon north of Wildcat Peak (UNLV), Razorback Ridge (UNLV).

Brickellia longifolia s. Wats.

Longleaf brickel1-bush

[=Coleosanthus Iongifolia (S. Wats.) Kuntze]

Crescent Cliff(UNLV), Chuckwalla Canyon(UNLV), Beatty Wash(UNLV), Meiklejohn Mtn. (UNLV), Tates Wash (UNLV).

Brickellia microphylla (Nutt.) Gray

Rough brickell-bush

[=Bulbostylis microphyl]us Nutt.]

Bare Mtn. (JCB), N. Yucca Mtn. (JCB), Specie Spring(UNLV), Fluorspar Canyon(UNLV), Tates Wash (UNLV), Yucca Mtn. (UNLV), Busted Butte(UNLV), Chuckwalla Canyon(UNLV), Beatty Wash(UNLV), Solitario Canyon(UNLV), Yucca Mtn. Ridge (UNLV), northeastern base of Yucca Mtn. (UNLV), Tates Wash (UNLV-C).

Brickellia multiflora Kell.

Bare Mtn. (JCB), North Yucca Mtn. (JCB).

Brickellia oblongifolia

Mojave brickell-bush

var. linifolia (D. C. Eat.) Rob.

Forty-Mile Canyon drainage(JCB).

Brickellia watsonii Rob.

Bare Mtn. (JCB), North Yucca Mtn. (JCB).

\section{Calycoseris}

Calycoseris parryi Gray

Yucca Mtn. Ridge (UNLV-C), northeastern base of Yucca Mtn. (UNLV), Meiklejohn Mtn. (UNLV).

Calycoseris wrightii Gray

Pale tackplant

Beatty Mtn. (JCB), Yucca Mtn. (O\&C), southern base of Yucca Mtn. (UNLV), 
southern base of Yucca Mtn. (UNLV-C).

\section{Chaenactis}

Chaenactis carphoclinia. Gray

Bare Mtn. (JCB), Yucca Mtn..(O\&C), Beatty Wash (UNLV).

Chaenactis Eremontii Gray

Desert pincushion

Below Bare Mtn. (JCB), Crater Flat (JCB, UNLV), Yucca Mtn. (O\&C, UNLV), Busted Butte(UNLV), Chuckwalla Canyon(UNLV), Forty-Mile Wash (UNLV), Beatty Wash(UNLV), southern base of Yucca Mtn. (UNLV), Yucca Mtn. Ridge(UNLV), Meiklejohn Mtn. (UNLV) .

Chaenactis macrantha D.C. Eat.

Southern base of Yucca Mtn. (UNLV-C), Meiklejohn Mtn. (UNLV), Razorback Ridge (UNLV).

Chaenactis stevioides Hook. \& Arn.

Stevia dusty-maiden Fluorspar Canyon(JCB), Tates Wash(JCB), Beatty Wash(UNLV-C), Yucca Mtn. Ridge (UNLV-C), northeastern base of Yucca Mtn. (UNLV), Mickeljohn Mtn. (UNLV-C), Razorback Ridge (UNLV).

Chaenactis xantiana Gray

Below North Yucca Mtn. (JCB), Beatty Wash(JCB), Yucca Mtn. (UNLV-C).

\section{Chrysothamnus}

Chrysothamnus nauseosus

ssp. heloleucus (Gray) Hall \& Clem.

Yucca Mtn. (JCB), Bare Mtn. (JCB).

Chrysothamnus nauseosus

ssp. leiospermus (Gray) Hall \& Clem.

[=Bigelovia leiosperma Gray;

Bigelovia lejosperma var. abbreviata Jones;

C. nauseosus var. abbreviata (Jones) Welsh]

Bare Mtn. (JCB), Yucca Mtn. (JCB), Crater Flat(UNLV), Fluorspar Canyon(UNLV), Tates Wash(UNLV), Crescent Cliff(UNLV), Tarantula Canyon(UNLV), Chuckwalla Canyon(UNLV), Yucca Mtn. (UNLV), Beatty Wash (UNLV), Solitario Canyon (UNLV), canyon north of Wildcat Peak (UNLV), Meiklejohn Mtn. (UNLV), Razorback Ridge(UNLV), Tates Wash(UNLV).

Chrysothamnus paniculatus (Gray) Hall

Mojave rabbitbrush

[=Bigelovia paniculata Gray;

Chrysothamnus oliganthus A. Nels.]

Below Bare Mtn. (JCB), Chuckwalla Canyon (JCB, UNLV), Tarantula Canyon(JCB, UNLV), Forty-Mile Wash(UNLV), Beatty Wash(UNLV), canyon north of Wildcat Peak(UNLV), northeastern base of Yucca Mtn. (UNLV), Tates Wash (UNLV-C).

Chrysothamnus teretifolius (Dur. \& Hilg.) Hall

Bare Mtn. (JCB), Chuckwalla Canyon(UNLV), Fluorspar Canyon(UNLV), Tates Wash(UNLV), Crescent Cliff(UNLV), Tarantula Canyon(UNLV), Yucca Mtn. (O\&C, UNLV), Busted Butte(UNLV), Beatty Wash(UNLV), Solitario 
Canyon(UNLV), canyon north of Wildcat Peak(UNLV), Yucca Mtn. Ridge(UNLV), Meiklejohn Mtn. (UNLV), Razorback Ridge(UNLV), Tates Wash (UNLV).

Chrysothamnus viscidiflorus.

Yellow rabbitbrush

ssp. stenophyllus (Gray) Hall \& Clem.

[=Bigelovia douglasii var. stenophylla Gray;

C. visidiflorus var. stenophylla (Gray) Hall \& Clem.

c. visidiflorus var. axillaris (Keck) L. C. Anderson;

c. auxillaris Keck]

Fluorspar Canyon(UNLV), Tates Wash(UNLV), Crescent Cliff(UNLV), Tarantula Canyon(UNLV), Yucca Mtn. (O\&C, UNLV), Chuckwalla Canyon(UNLV), Beatty Wash(UNLV), Meiklejohn Mtn. (UNLV), Tates Wash (UNLV-C).

Cirsium

Cirsium neomexicanum Gray

New Mexico thistle Chuckwalla Canyon(UNLV-C), Specie spring(UNLV), Tates Wash(UNLV), Crescent Cliff(UNLV), Beatty Wash(UNLV), Solitario Canyon(UNLV), northeastern base of Yucca Mtn. (UNLV), Meiklejohn Mtn. (UNLV), Razorback Ridge (UNLV), Tates Wash(UNLV).

Conyza

Conyza canadensis (L.) Cronq.

Horseweed

[=Erigeron canadensis (L.) Cronq.]

Forty-Mile Wash(UNLV), Specie Spring(UNLV-C).

Encelia

Encelia farinosa Gray

Brittlebush, incienso Northern Amargosa Valley(JCB), Crater Flat (UNLV).

Encelia Erutescens Gray

Bush encelia

var. Erutescens

[= Simsia frutescens Gray;

E. Erutescens var. resinosa Jones]

Northern Amargosa Valley (JCB).

Encelia virginensis

ssp. actoni (Elmer) Keck

$[=E$. Erutescens var. virginensis (A. Nels.) Blake]

Northern Bare Mtn. (JCB), West Crater Flat (JCB), Yucca Mtn. (O\&C), Beatty Wash (UNLV-C).

Encelia virginensis A. Nels.

ssp. virginensis

[=E. Erutescens var. virginensis (A. Nels.) Blake]

Northern Amargosa valley(JCB), Black Marble Canyon(UNLV), Crater Flat(UNLV), Chuckwalla Canyon(UNLV), Specie spring(UNLV), Fluorspar Canyon(UNLV), Tates Wash(UNLV), Tarantula Canyon(UNLV), Yucca Mtn.(UNLV), Busted Butte(UNLV), Forty-Mile Wash(UNLV), Beatty Wash(UNLV-C), Solitario Canyon(UNLV), canyon north of wildcat Peak (UNLV), Yucca Mtn. Ridge(UNLV), northeastern base of Yucca Mtn. (UNLV), Meiklejohn Mtn. (UNLV), Razorback Ridge (UNLV) . 


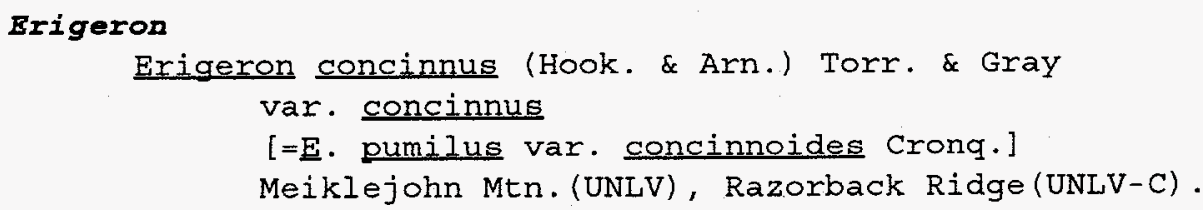

\section{Haplopappus}

Haplopappus brickelloides Blake

[=Hazardia brickelloides (S.F. Blake) W. Clark]

Bare Mtn. (JCB), Black Marble Mtn. (UNLV), Chuckwalla Canyon(UNLV), canyon north of Wildcat Peak (UNLV).

Haplopappus cooperi [Gray) Hall

[=Ericameria cooperi (Gray) Hall]

Crater Flat (JCB), North Crater Flat(UNLV), Chuckwalla Canyon(UNLV), Fluorspar Canyon(UNLV), Tates Wash(UNLV), Crescent Cliff(UNLV), FortyMile Wash (UNLV-C), Yucca Mtn. (O\&C, UNLV-C), Busted Butte (UNLV), Beatty Wash(UNLV), Solitario Canyon(UNLV), canyon north of Wildcat Peak(UNLV), northeastern base of Yucca Mtn. (UNLV), Meiklejohn Mtn. (UNLV), Tates Wash (UNLV-C) .

Haplopappus cuneatus Gray

[=Ericameria cuneata (Gray) McClatchie] 


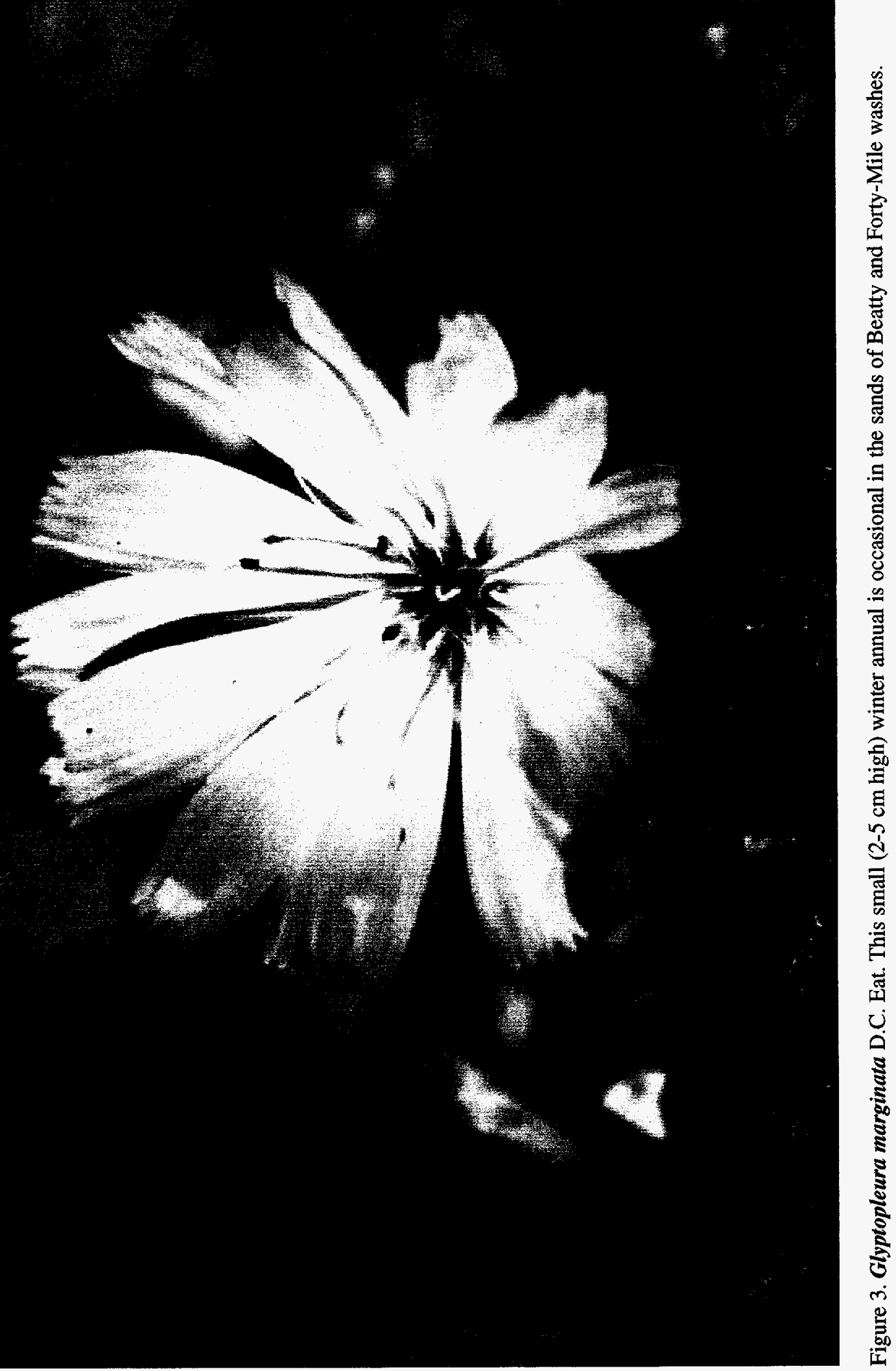


Specie Spring(UNLV-C), Crescent Cliff(UNLV), Chuckwalla Canyon(UNLV), canyon north of Wildcat Peak(UNLV), Razorback Ridge(UNLV).

Haplopappus linearifolius DC.

Interior goldenbush

[=Ericameria linearifolia (DC.) Urb.\& Wussow]

Northern Bare Mtn. (JCB), Northern Yucca Mtn. (JCB), Specie Spring(UNLVC), Fluorspar Canyon(UNLV), Tates Wash(UNLV), Crescent Cliff(UNLV), Yucca Mtn. (O\&C, UNLV), Chuckwalla Canyon (UNLV), Beatty Wash (JCB, UNLV-C), Solitario Canyon(UNLV), Busted Butte(UNLV), southern base of Yucca Mtn. (UNLV), Yucca Mtn. Ridge(UNLV), northeastern base of Yucca Mtn. (UNLV), Meiklejohn Mtn. (UNLV), Razorback Ridge(UNLV), Tates Wash (UNLV).

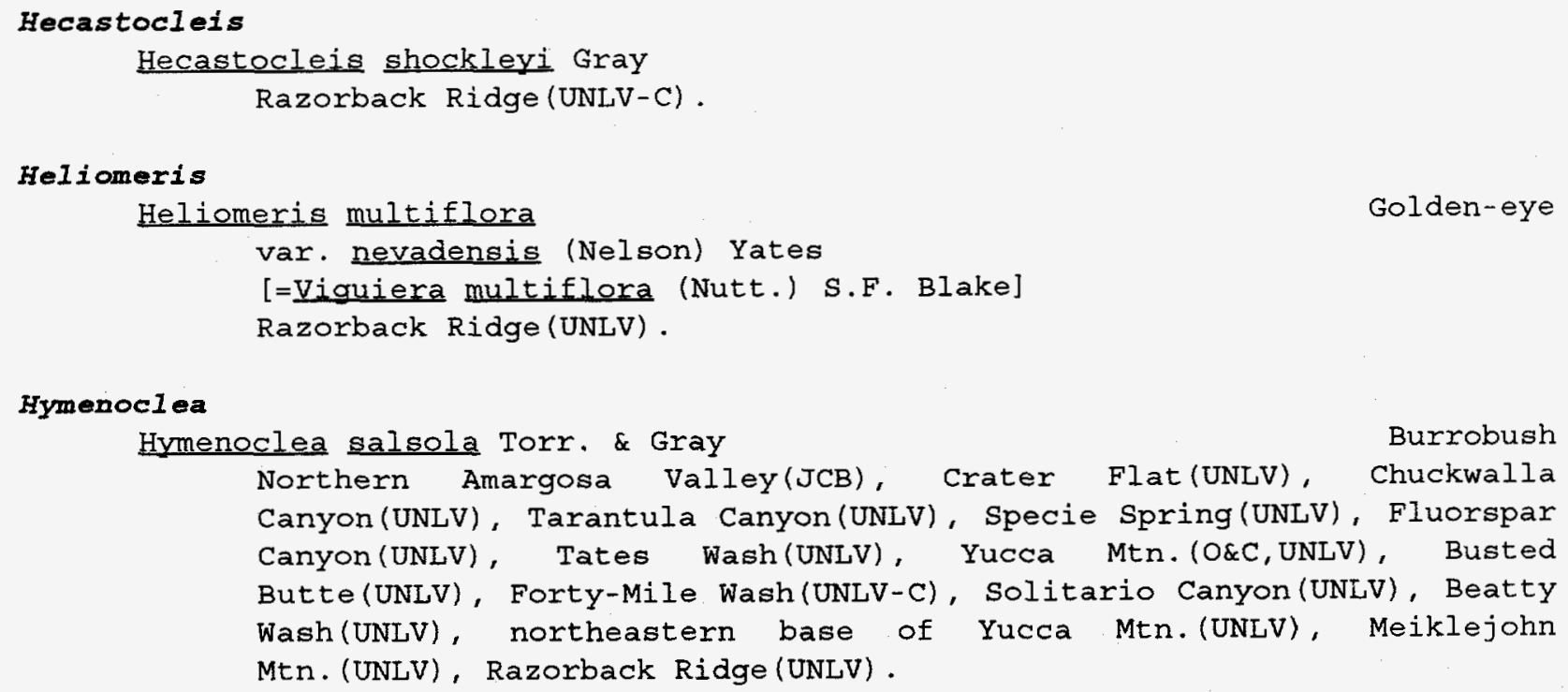

Machaeranthera

Machaeranthera canescens (Pursh) Gray

Hoary-aster

[ = Aster canescens Pursh]

Northwest Yucca Mtn. (JCB), Tates Wash(UNLV), Forty-Mile Wash(UNLV-C) Yucca Mtn. (O\&C, UNLV), Busted Butte (UNLV), Beatty Wash(UNLV), Solitario Canyon(UNLV), Yucca Mtn. Ridge (UNLV).

Machaeranthera tortifolia (Gray) Cronq. \& Keck Mojave-aster

var. tortifolia

[=Xylorhiza tortifolia (Torr. \& Gray) Greene;

Aster abatus Blake;

Haplopappus tortifolius Torr. \& Gray;

Xylorhiza lanceolata Rydb.]

Crater Flat (UNLV), Black Marble Canyon(UNLV), Tates Wash(UNLV), Yucca Mtn. (O\&C, UNLV-C), Busted Butte(UNLV), Beatty Wash(UNLV), solitario Canyon(UNLV), canyon north of Wildcat Peak(UNLV), southern base of Yucca Mtn. (UNLV), Meiklejohn Mtn. (UNLV).

Malacothrix

Malacothrix coulteri Gray 
Beatty Wash(UNLV-C), southern base of Yucca Mtn. (UNLV-C), Yucca Mtn. Ridge (UNLV).

Malacothrix glabrata Gray

Desert-dandelion

[= Malacothrix californica var. glabrata D.C. Eaton]

Crater Flat (UNLV), Yucca Mtn. (JCB, O\&C, UNLV), Chuckwalla Canyon (UNLV), Beatty Wash(UNLV), Busted Butte(UNLV), Yucca Mtn. Ridge(UNLV),

Meiklejohn Mtn. (UNLV), Razorback Ridge(UNLV).

Malacothrix sonchoides (Nutt.) Torr. \& Gray

[=Leptoseris sonchoides Nutt.]

Beatty Wash (JCB, UNLV-C), Yucca Mtn. (O\&C), Cresent Cliff(UNLV-C), Forty-Mile Wash(UNLV-C), Busted Butte(UNLV).

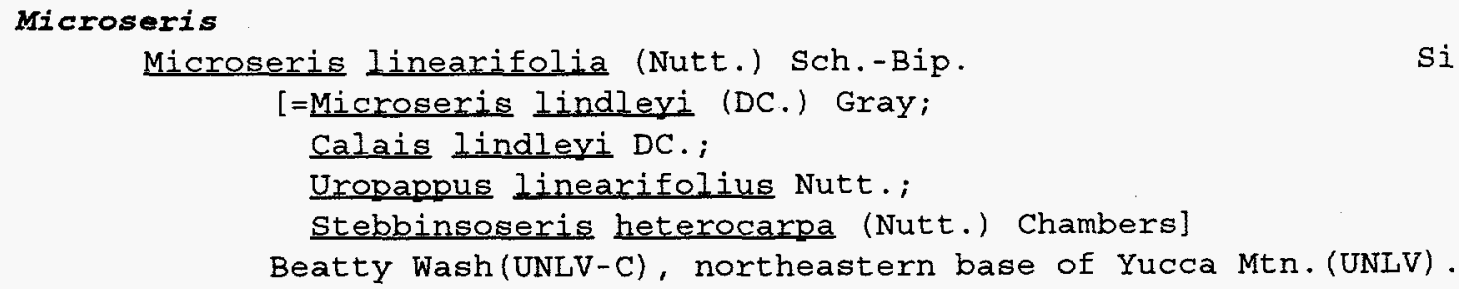

Monoptilon

Monoptilon bellidiforme Torr. \& Gray ex Gray

Desert-star Chuckwalla Canyon(UNLV), Solitario Canyon(UNLV), Forty-Mile Wash (UNLV-C), Beatty Wash (UNLV-C), Busted Butte(UNLV), northeastern base of Yucca Mtn. (UNLV).

Perityle

Perityle intricata (Brandeg.) Shinners

[= Perityle megalocephala var. oligophylla (Brandeg.) Keck;

Laphamia megalocephala var. intricata (Brandeg.) Keck]

Canyon north of Wildcat Peak (UNLV-C).

Perityle megalocephala (S. Wats.) Macbr.

var. megalocephala

Black Marble Mtn. (UNLV).

Peucephyl Ium

Peucephyllum schottii (Gray) Gray

[= Psathyrotes schotti Gray]

Canyon north of Wildcat Peak (UNLV).

Pygmy-cedar

Prenanthella

Prenanthella exiqua (Gray) Rydb.

[=Prenanthes exigua Gray;

Iyogdesmia exigua (Gray) Gray]

North Amargosa Valley (JCB), Yucca Mtn. (O\&C), Forty-Mile Wash(UNLV), Beatty Wash(UNLV), northeastern base of Yucca Mtn. (UNLV), Meiklejohn Mtn. (UNLV), Razorback Ridge (UNLV).

Rafinesquia 
Rafinesquia neomexicana Gray

Desert-chicory South Crater Flat (JCB, UNLV), Yucca Mtn. (O\&C), Forty-Mile Wash(UNLV), Beatty Wash(UNLV), Busted Butte(UNLV), southern base of Yucca Mtn. (UNLV), Meiklejohn Mtn. (UNLV), Razorback Ridge(UNLV).

Senecio

Senecio douglasii

Douglas' groundsel

var. monoensis (Greene) Jeps.

$[=\underline{S}$. Elaccidus var. monoensis (Greene) Turner \& Barkley]

Yucca Mtn. (JCB), Tates Wash(UNLV-C), Chuckwalla Canyon(UNLV), Busted Butte (UNLV), canyon north of Wildcat Peak(UNLV), Meiklejohn Mtn. (UNLV).

Senecio multilobatus Torr. \& Gray ex Gray

Groundsel

[=․․ Iapidum Greenman]

Yucca Mtn. (JCB), Beatty Wash(JCB), Yucca Mtn. Ridge(UNLV-C), northeastern base of Yucca Mtn. (UNLV).

Stephanomeria

Stephanomeria parryi Gray

Parry's-wirelettuce Yucca Mtn. (UNLV-C), northeastern base of Yucca Mtn. (UNLV), Meiklejohn Mtn. (UNLV) .

Stephanomeria pauciflora

Wirelettuce

var. parishii (Jepson) Munz

[=Prenanthes pauciflora Torr.]

Northern Amargosa Valley(JCB), Crater Flat(UNLV), Chuckwalla Canyon(UNLV), Tates Wash(UNLV), Crescent Cliff(UNLV), Yucca Mtn. (O\&C, UNLV), Busted Butte(UNLV), Forty-Mile Wash(UNLV), Beatty Wash (UNLV), Solitario Canyon(UNLV-C), canyon north of wildcat Peak (UNLV), southern base of Yucca Mtn. (UNLV), northeastern base of Yucca Mtn. (UNLV), Meiklejohn Mtn. (UNLV), Razorback Ridge(UNLV), Tates Wash (UNLV) .

stylocline

Stylocline micropoides Gray

Desert nest-straw Specie Spring(UNLV), Crescent Cliff(UNLV), Beatty Wash(UNLV), Yucca Mtn. (O\&C), Forty-Mile Wash (UNLV-C), Yucca Mtn. Ridge(UNLV), northeastern base of Yucca Mtn. (UNLV).

Syntrichopappus

Syntrichopapous Eremontii Gray

Fluorspar Canyon(UNLV-C), Tates Wash(UNLV), Yucca Mtn. (O\&C, UNLV), Beatty Wash(UNLV-C), Solitario Canyon(UNLV), Yucca Mtn. Ridge(UNLV), northeastern base of Yucca Mtn. (UNLV), Razorback Ridge (UNLV).

Tetradymia

Tetradymia axillaris A. Nels.

Longspine horsebrush

Chuckwalla Canyon(UNLV), Fluorspar Canyon(UNLV), Tates Wash(UNLV), Tarantula Canyon(UNLV), Yucca Mtn. (O\&C, UNLV-C), Busted Butte (UNLV), Beatty Wash(UNLV-C), Solitario Canyon(UNLV), Yucca Mtn. Ridge(UNLV), northeastern base of Yucca Mtn. (UNLV-C), Meiklejohn Mtn. (UNLV), Razorback Ridge (UNLV). 


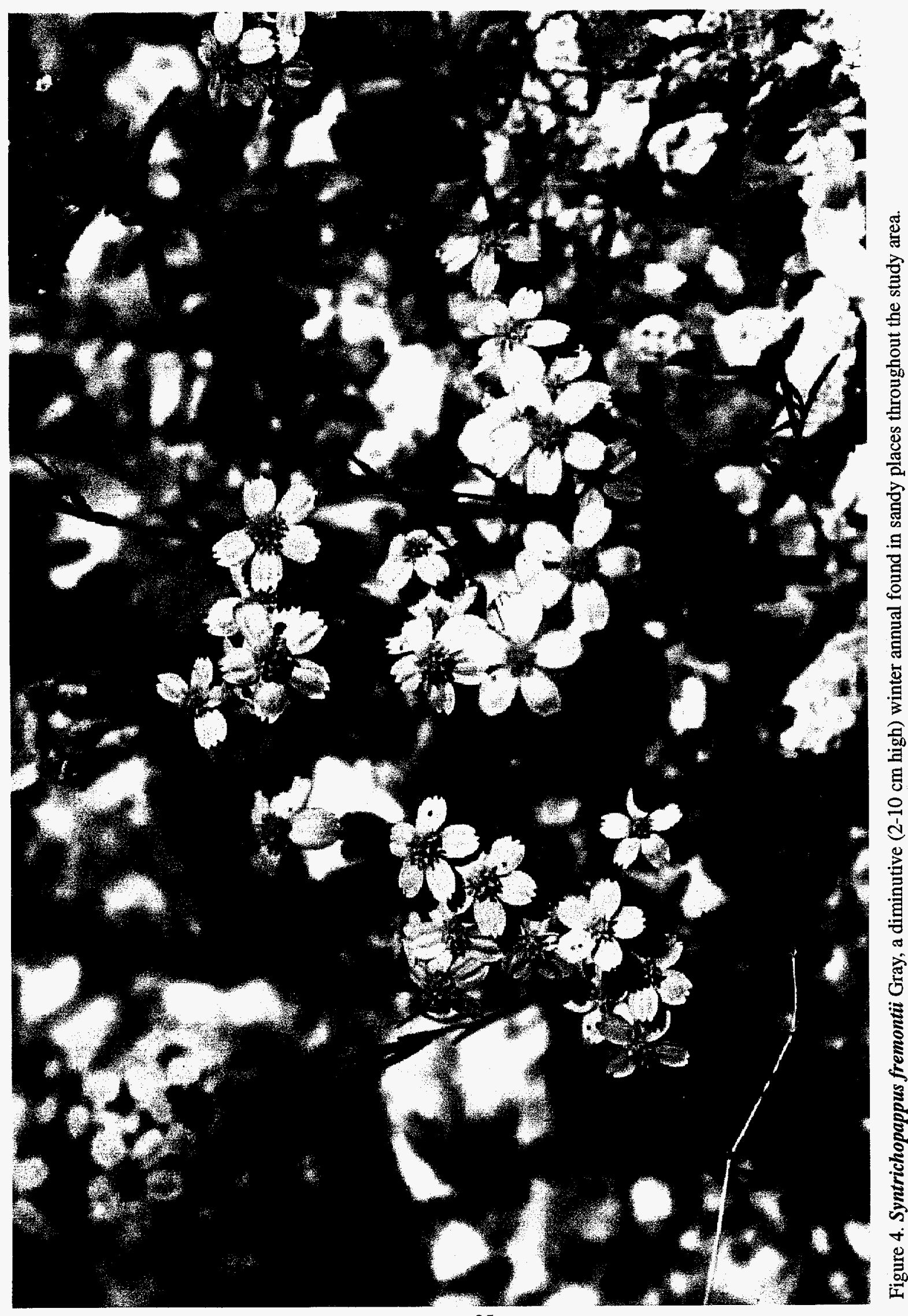


Tetradymia canescens DC.

Beatty Wash (UNLV).

Tetradymia glabrata Torr. \& Gray

Littleleaf horsebush Tates Wash(UNLV), Crescent Cliff (UNLV), Tarantula Canyon(UNLV), Beatty Wash(UNLV-C), Solitario Canyon(UNLV), northeastern base of Yucca Mtn. (UNLV), Tates Wash (UNLV).

Viguiera

Viguiera reticulata $S$. Wats.

Crater Flat(UNLV), Chuckwalla Canyon(UNLV), Tarantula Canyon(UNLV), Beatty Wash(UNLV), canyon north of Wildcat Peak(UNLV-C), Meiklejohn Mtn. (UNLV).

\section{Boraginaceae Borage Family}

\section{Amsinckia}

Amsinckia intermedia F.\&M.

Yucca Mtn. Ridge(UNLV-C), northeastern base of Yucca Mtn(UNLV).

Amsinckia tessellata Gray

Rough fiddleneck

$[=\underline{A}$. collina Greene;

A. pustulata Heller;

A. Conica Suksd.;

A. utahensis Suksd.]

Crater Flat(UNLV), Chuckwalla Canyon(UNLV), Tates Wash(UNLV), Yucca Mtn. (O\&C, UNLV-C), Beatty Wash (UNLV), Solitario Canyon(UNLV), Forty-Mile Wash(UNLV), southern base of Yucca Mtn. (UNLV), Yucca Mtn. Ridge (UNLV), northeastern base of Yucca Mtn. (UNLV), Meiklejohn Mtn. (UNLV), Specie Spring (UNLV), Tates Wash (UNLV).

\section{Coldenia}

Coldenia nuttallii Hook.

[= Tiquilia nutta]lii (Hook.) Richards.]

Red Cinder Cone (South Yucca Mtn.) (JCB), Forty-Mile Wash(UNLV-C), Busted Butte (UNLV-C).

Coldenia plicata (Torr.) Cov.

[=Tiquilia plicata (Torr.) A. Richards.]

Busted Butte(UNLV), Beatty Wash(UNLV).

\section{Cryptantha}

Cryotantha angustifolia (Torr.) Greene

Narrowleaf cryptanth

[ Eritrichium angustifolium Torr.;

Krynitzkia angustifolia Gray]

Bare Mtn. Area of North Yucca Mtn. (JCB), Chuckwalla Canyon (UNLV),

Yucca Mtn. (O\&C) .

Cryptantha barbigera (Gray) Greene

Yucca Mtn. Ridge (UNLV-C), northeastern base of Yucca Mtn. (UNLV), Meiklejohn Mtn. (UNLV), Specie Spring(UNLV-C), Razorback Ridge (UNLV-C) . 
Cryptantha circumscissa (Hook. \& Arn.) Jtn.

Opening cryptanth

[= ithospermum circumscissum H. \& A.;

Cryotantha depressa $A$. Nels.]

Below North Yucca Mtn. (JCB), Yucca Mtn. (UNLV), Beatty Wash(UNLV), Forty-Mile Wash (UNLV-C), Busted Butte(UNLV), northeastern base of Yucca Mtn. (UNLV), Meiklejohn Mtn. (UNLV), Razorback Ridge (UNLV).

Cryptantyha confertiflora (Greene) Pays.

Northeastern base of Yucca Mtn. (UNLV-C), Meiklejohn Mtn. (UNLV), Razorback Ridge (UNLV).

Cryptantha decipiens (M. E. Jones) Heller

Beguiling cryptanth

[= Krynitizkia decipens Jones]

Beatty Wash(JCB), Yucca Mtn. Ridge(UNLV-C), Specie Spring(UNLV-C).

Cryotantha dumetorum (Greene ex Gray) Greene

[=Krynitizkia dumetorum Greene]

Busted Butte (UNLV), Beatty Wash (JCB, UNLV-C).

Cryotantha Elavoculata (A. Nels.) Pays.

Yellow-eye cryptanth

[loreocarya flavoculata A. Nels.]

Chuckwalla Canyon(UNLV-C), Tarantula Canyon(UNLV), northeastern base of Yucca Mtn. (UNLV-C), Tates Wash (UNLV).

Cryptantha gracilis Osterh.

Razorback Ridge(UNLV-C).

Cryptantha maritima (Greene) Greene

Dye cryptanth

[=Eritrichium micranthum Torr .;

Eremocarya muricata Rydb.]

Yucca Mtn. (JCB), Bare Mtn. (JCB), Busted Butte (UNLV-C), southern base of Yucca Mtn. (UNLV).

Cryptantha micrantha (Torr.) I.M. Johnston

[=Eritrichium micrantha Torr.]

Crater Flat (UNLV), Forty-Mile Wash(UNLV), Beatty Wash(UNLV), Busted Butte (UNLV), northeastern base of Yucca Mtn. (UNLV).

Cryptantha nevadensis Nels. \& Kenn.

Nevada cryptanth

var. nevadensis

[= Cryptantha leptophy]la Rydb.]

Crescent Cliff(UNLV), Northern Amargosa Valley(JCB), Yucca

Mtn. $(O \& C)$, Forty-Mile Wash(UNLV-C), Beatty Wash(UNLV-C), Yucca Mtn. Ridge (UNLV-C), Meiklejohn Mtn. (UNLV), Razorback Ridge (UNLV).

Cryptantha pterocarya (Torr.) Greene

wing-nut cryptanth

[=Eritrichium pterocaryum Torr.;

Eritrichium pterocarnum var. pectinatum Gray]

Yucca Mtn. (O\&C, UNLV), Busted Butte (UNLV-C), Beatty Wash(UNLV-C), Crater Flat (UNLV-C), Forty-Mile Wash(UNLV), southern base of Yucca Mtn. (UNLV), Yucca Mtn. Ridge(UNLV), northeastern base of Yucca Mtn. (UNLV), Meiklejohn Mtn. (UNLV), Specie Spring(UNLV-C) . 
Cryptantha racemosa (S. Wats.) Greene

[=Eritrichium racemosum Wats.]

Canyon north of Wildcat Peak (UNLV).

Cryptantha recurvata Cov.

Recurved cryptanth

Crater Flat (JCB, UNLV-C), Forty-Mile Wash(UNLV-C), Beatty Wash(UNLV),

Busted Butte(UNLV), Meiklejohn Mtn. (UNLV).

Cryptantha utahensis (Gray) Greene

Utah cryptanth

[= Krynitzkia utahensis Gray;

Eritrichium holopterum var. submolle Gray]

Beatty Wash (JCB, UNLV), Yucca Mtn. Ridge(UNLV), Meiklejohn Mtn. (UNLV), Razorback Ridge (UNLV).

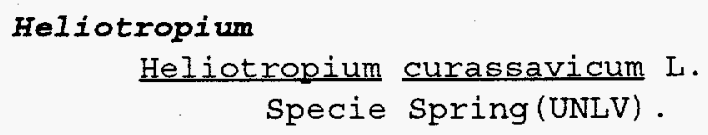

\section{Pectocarya}

Pectocarya heterocarpa (Jtn.) Jtn.

Combseed

$[=$ P. penicillata var. heterocarpa Johnston]

Northern Amargosa Valley(JCB), Yucca Mtn.(O\&C), Forty-Mile Wash

(UNLV-C), Beatty Wash (UNLV-C).

Pectocarya platycarpa (Munz \& Jtn.) Munz \& Jtn.

Flattened combseed

[=Pectocarya gracilis var. platycarpa Munz \& Johnston]

Specie Spring(UNLV-C), Bare Mtn. (JCB), Beatty Wash(JCB).

Pectocarya recurvata Jtn.

Bent combseed Crater Flat (UNLV-C), Yucca Mtn. (O\&C, UNLV-C), Solitario Canyon(UNLV), Forty-Mile Wash(UNLV-C), Busted Butte(UNLV), southern base of Yucca Mtn. (UNLV), Meiklejohn Mtn. (UNLV), Razorback Ridge(UNLV).

Pectocarya setosa Gray

Saucer combseed

[ = Pectocarya setosa var. aperta Johnston

Pectocarya setosa var. holoptera Johnston;

Gruvelia setosa (Gray) Rydb.]

Yucca Mtn. (JCB, O\&C, UNLV-C), Chuckwalla Canyon(UNLV-C), Beatty Wash (UNLV-C), Solitario Canyon(UNLV), Yucca Mtn. Ridge(UNLV), northeastern base of Yucca Mtn. (UNLV), Meiklejohn Mtn. (UNLV), Specie Spring(UNLV-C), Razorback Ridge(UNLV).

\section{Plagiobothrys}

Plagiobothrys arizonicus (Gray) Greene ex Gray

[=Eritrichium canescens var. arizonicum Gray]

Stainplant

Specie Spring (UNLV-C), Tates Wash (UNLV).

plagiobothrys jonesii (Gray) Gray

Popcornflower

[= Sonnea jonesii (Gray) Greene]

Crater Flat (UNLC-C), Bare Mtn. (JCB), Beatty Wash(JCB, UNLV-C), Busted Butte(UNLV), Meiklejohn Mtn. (UNLV). 


\section{Arabis}

Arabis perennans $S$. Wats.

[=Boecher perennans (S. Wats.) W. A. Weber;

A. arcuata var. perennans (S. Wats.) Jones;

B. gracilenta Greene;

A. recondita Greene;

A. angulata Greene ex Woot. \& Standl.;

A. falactoria Rollins]

Specie Spring(UNLV-C). Tates Wash(UNLV), Tarantula Canyon(UNLV), Chuckwalla Canyon (UNLV-C).

Arabis pulchra

Rockcress

var. gracilis M. E. Jones

Cresent Cliff (UNLV-C).

Arabis pulchra

Rockcress

var. munciensis $M . E$. Jones

North Yucca Mtn. (JCB), Fluorspar Canyon(UNLV), Yucca Mtn. (O\&C), Cresent Cliff (UNLV-C), Beatty Wash(UNLV-C), Meiklejohn Mtn. (UNLV-C).

\section{Caulanthus}

Caulanthus cooperi (S. Wats.) Pays.

[=Thelypodium cooperi S. Wats;

Guillenia cooperi (S. Wats.) Greene]

Crater Flat (JCB), Yucca Mtn. (O\&C), Beatty Wash(UNLV-C), northeastern base of Yucca Mtn. (UNLV).

Caulanthus Iasiophyllus

var. utahensis (Rydb.) Pays.

[ = Turritis lasiophylla Hook. \& Arn.;

Thelypodium lasiophyllum (Hook. \& Arn.) Greene;

Sisymbrium lasiophyllum (Hook. \& Arn.) Brandeg.;

Guillenia lasiophylla (Hook. \& Arn.) Greene]

Beatty Wash (UNIV), Yucca Mtn. (O\&C), Crater Flat (UNLV-C).

Caulanthus pilosus S. Wats.

[=Streptanthus pilosus (S. Wats.) Jepson]

Beatty Wash (UNLV-C).

Descurainia

Descurainia pinnata

Pinnate tansy-mustard ssp. glabra (Woot. \& Standl.) Delt.

Yucca Flat (JCB), Crater Flat (UNLV-C), Yucca Mtn. Ridge(UNLV).

\section{Descurainia pinnata}

ssp. halictorum (Ckll.) Detl.

Specie Spring(UNLV), Beatty Wash(JCB, UNLV-C), Yucca Mtn. (O\&C), Crater Flat (UNLV-C), Forty-Mile Wash(UNLV), northeastern base of Yucca Mtn. (UNLV). 
Descurainia sophia (L.) Webb.

Yucca Mtn. Ridge(UNLV), northeastern base of Yucca Mtn. (UNLV-C).

\section{Dithyrea}

Dithyrea californica Harv.

Spectacle-pod Northeastern base of Yucca Mtn. (UNLV).

\section{Lepidium}

Lepidium flavum Torr.

var. flavum

North Amargosa Valley (JCB).

Lepidium Eremontii S. Wats.

Pepper-grass Bare Mtn. (JCB), Black Marble Mtn. (UNLV), Chuckwalla Canyon(UNLV), Yucca Mtn. (UNLV), Busted Butte(UNLV), Forty-Mile Wash(UNLV), Beatty Wash (UNLV-C) .

Lepidium lasiocarpum Nutt. ex Torr. \& Gray North Amargosa Valley(JCB), Yucca Mtn. (O\&C, UNLV), Solitario Canyon(UNLV), Crater Flat(UNLV-C), Forty-Mile Wash(UNLV), Busted Butte(UNLV), northeastern base of Yucca Mtn. (UNLV), Meiklejohn Mtn. (UNLV) .

Malacomia

Malacomia africana (L.) R. Br.

Cresent Cliff (UNLV-C).

Sisymbrium

Sisymbrium altissimum L.

Tumbling-mustard

[ Norta altissima Britt.]

Specie Spring(UNLV), Tates Wash(UNLV), Yucca Mtn. (O\&C), Forty-Mile Wash (UNLV-C), northeastern base of Yucca Mtn. (UNLV).

Sisymbrium irio L.

London-rocket

Specie spring(UNLV).

Stanleya

Stanleya pinnata

Prince's-plume

var. inyoensis (Munz \& Roos) Reveal

Below North Yucca Mtn. (JCB), Tates Wash (UNLV), Yucca Mtn. (UNLV), Beatty

Wash(UNLV-C), Meiklejohn Mtn. (UNLV), Razorback Ridge(UNLV).

Streptanthella

Streptanthella longirostris Nutt.

$[=$ Arabis longirostris S. Wats.;

Streptanthus longicostris (S. Wats.) S. Wats.;

Thelypodium longirostris (S. Wats.) Jepson]

Crater Flat (JCB, UNLV-C), Busted Butte(UNLV), Forty-Mile Wash(UNLV),

Beatty Wash (UNLV).

Streptanthus

Streptanthus cordatus Nutt. ex Torr. \& Gray 


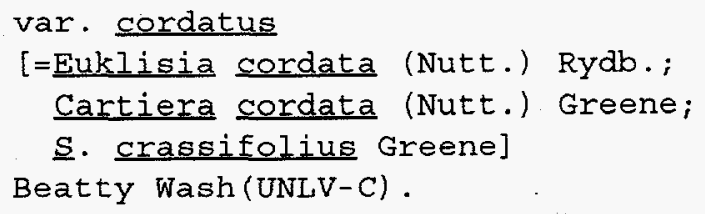

Cactaceae Cactus Family

\section{Echinocactus}

Echinocactus polycephalus Engelm. \& Bigel.

Cottontop Black Marble Mtn. (UNLV), Crater Flat(UNLV), Chuckwalla Canyon(UNLV), Crescent Cliff(UNLV), Tarantula Canyon(UNLV), Yucca Mtn. (O\&C, UNLV), Busted Butte(UNLV), Beatty Wash(UNLV), Solitario Canyon(UNLV), canyon north of Wildcat Peak (UNLV), southern base of Yucca Mtn. (UNLV), northeastern base of Yucca Mtn. (UNLV), Razorback Ridge(UNLV), Tates Wash (UNLV).

\section{Echinocereus}

Echinocereus engelmannii

var. chrysocentrus (Engelm. \& Bigel.) Engelm.

Hedgehog cactus

[=Cereus engelmannii var. chrysocentrus Engelm. \& Bigel.;

E. engelmannil var. purpureus $L$. Benson]

Steves Pass (UNLV), Black Marble Canyon(UNLV), Chuckwalla Canyon(UNLV), Specie Spring(UNLV), Fluorspar Canyon(UNLV), Tates Wash (UNLV), Crescent Cliff(UNLV), Tarantula Canyon(UNLV), Yucca Mtn. (UNLV), Busted Butte (UNLV), Beatty Wash(UNLV), Solitario Canyon(UNLV), canyon north of Wildcat Peak (UNLV), Yucca Mtn. Ridge(UNLV), northeastern base of Yucca Mtn. (UNLV), Meiklejohn Mtn. (UNLV), Razorback Ridge(UNLV).

Echinocereus triglochidiatus Claretcup, mound cactus

var. melanacanthus (Engelm.) L. Benson

[=E. coccineus Engelm. var. melanacanthus Engelm.;

E. triglechidiatus var. inermis (K. Schum.) Rowley;

$E$. phoeniceus var. inermis $K$. Schum.]

Tarantula Canyon(UNLV-C), Solitario Canyon(UNLV), Meiklejohn Mtn. (UNLV), Razorback Ridge(UNLV).

Mammillaria

Mammillaria tetrancistra Engelm.

Fish-hook cactus

[=Phellosperma tetrancistra (Engelm.) Britt. \& Rose]

Crescent Cliff(UNLV), Busted Butte(UNLV), canyon north of wildcat Peak (UNLV-C). 


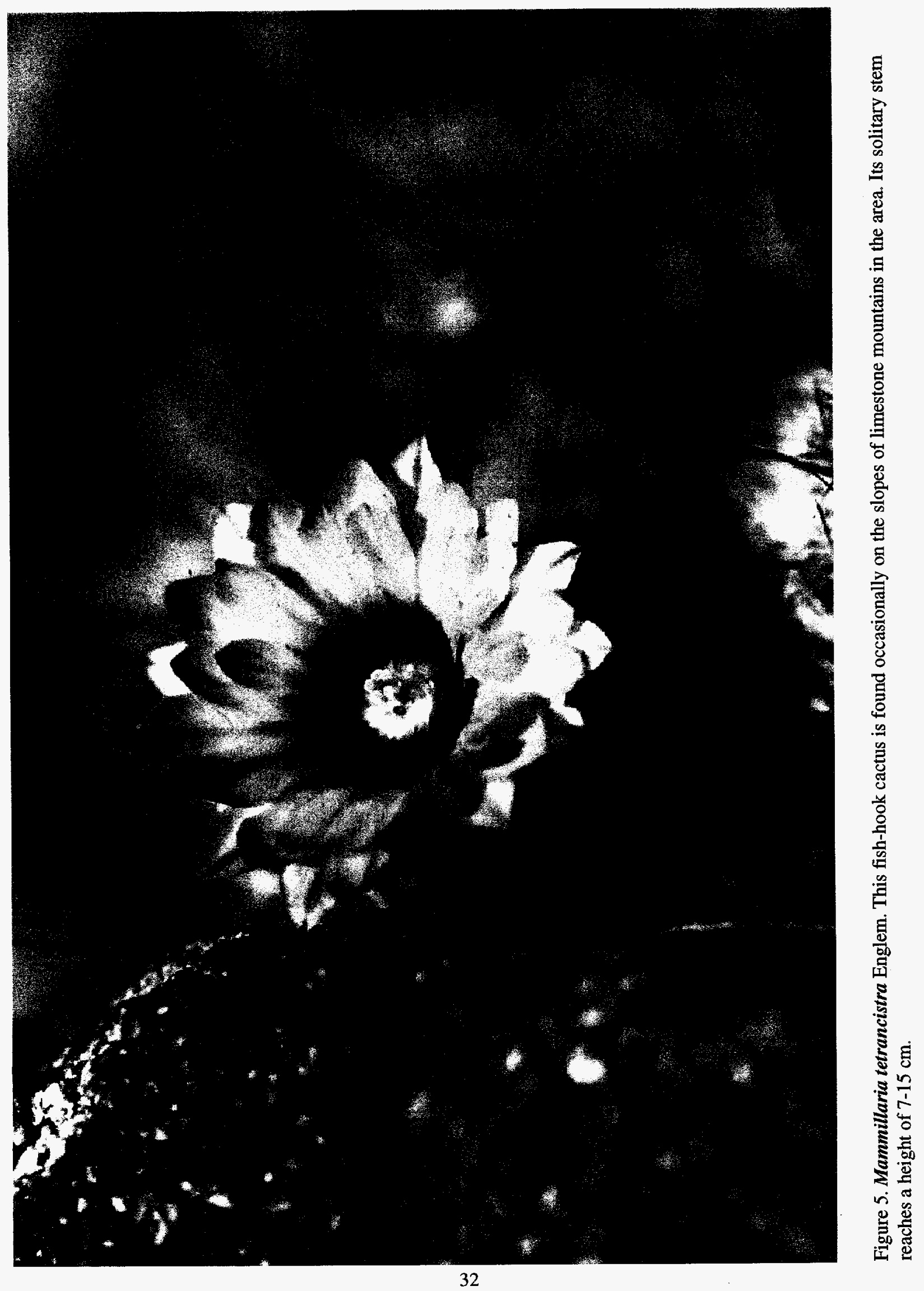


var. basilaris

Black Marble Mtn. (UNLV), Crater Flat (UNLV), Chuckwalla Canyon(UNLV), Fluorspar Canyon(UNLV), Tates Wash (UNLV), Tarantula Canyon (UNLV), Yucca Mtn. (O\&C, UNLV), Busted Butte(UNLV), Beatty Wash(UNLV), Solitario Canyon(UNLV), canyon north of Wildcat Peak(UNLV), Forty-Mile Wash(UNLV), southern base of Yucca Mtn. (UNLV), Yucca Mtn. Ridge(UNLV), northeastern base of Yucca Mtn. (UNLV).

opuntia echinocarpa Engelm. \& Bigel.

Silver cholla

var. echinocarpa

Steves Pass(UNLV), Black Marble Canyon(UNLV), Crater Flat (UNLV), Fluorspar Canyon(UNLV), Yucca Mtn. (O\&C), Tates Wash(UNLV), Beatty Wash(UNLV), canyon north of Wildcat Peak(UNLV), Forty-Mile Wash (UNLV), southern base of Yucca Mtn. (UNLV), northeastern base of Yucca Mtn. (UNLV) .

Opuntia erinacea Engelm. \& Bigel.

var. erinacea

$[=0$. ursina Weber in Boiss;

o. rubrifolia Engelm. ex Coult.;

o. hystricina sensu Utah authors]

Chuckwalla Canyon(UNLV-C), Specie Spring(UNLV), Crescent Cliff(UNLV), Tarantula Canyon(UNLV), Busted Butte(UNLV), Meiklejohn Mtn. (UNLV), Razorback Ridge (UNLV).

\section{Sclerocactus}

Sclerocactus polyancistrus (Engelm.) Britt. \& Rose Fish-hook cactus [=Echinocactus polyancistrus Engelm. \& Bigel.]

Crater Flat (UNLV), Fluorspar Canyon(UNLV), Specie Spring(UNLV-C), Tates Wash(UNLV), Yucca Mtn. (UNLV-C), Beatty Wash(UNLV), Solitario Canyon(UNLV), Mickeljohn Mtn. (UNLV).

Campanulaceae Bellflower Family

\section{Nemacladus}

Nemacladus glanduliferus

var, orientalis McVaugh

Chuckwalla Canyon(UNLV), Beatty Wash(UNLV-C), Solitario Canyon(UNLV), Busted Butte (UNLV-C), northeastern base of Yucca Mtn. (UNLV), Meiklejohn Mtn. (UNLV).

Nemacladus rubescens Greene

Yucca Mtn. (O\&C), Forty-Mile Wash(UNLV-C), Beatty Wash(UNLV), Busted Butte (UNLV-C).

Nemacladus sigmoides Robbins Yucca Mtn. (UNLV-C).

Capparaceae Caper Family 
Cleome lutea Hook.

Lower Forty-Mile Canyon Wash(UNLV).

Caprifoliaceae. Honeysuckle Family

Symphoricarpos

Symphoricarpos longiflorus Gray

Fragrant snowberry North Bare Mtn. (JCB), Tarantula Canyon(UNLV), Busted Butte(UNLV), Chuckwalla Canyon (UNLV-C), Beatty Wash (UNLV-C), northeastern base of Yucca Mtn. (UNLV).

\section{Caryophyllaceae Pink Family}

\section{Arenaria}

Arenaria congesta

Looseflower sandwort

var. subcongesta (S. Wats.) S. Wats.

[=A. Eendleri var. subcongesta $S$. Wats.]

Beatty Wash (UNLV-C).

Arenaria macradenia $S$. Wats.

Desert sandwort

var. macradenia

[=A. macradenia var. parishiorum Robinson

A. macradenia ssp. Eerrisiae Abrams]

Chuckwalla Canyon(UNLV-C), Specie Spring(UNLV), Crescent Cliff(UNLV),

Tarantula Canyon(UNLV), Beatty Wash(UNLV), canyon north of Wildcat Peak (UNLV-C), Meiklejohn Mtn. (UNLV), Razorback Ridge(UNLV-C), Tates Wash (UNLV).

Arenaria kingii (S. Wats.) M.E. Jones

var. glabrescens (S. Wats.) Maguire

Razorback Ridge (UNLV-C).

Celastraceae Staff-Tree Family

\section{Forsellesia}

Forsellesia nevadensis (Gray) Greene

Nevada greasebush

[=Glossopetalon meionandrum Koehne]

Specie Spring(UNLV), Tarantula Canyon(UNLV), northeastern base of Yucca Mtn. $($ UNLV-C).

\section{Chenopodiaceae Goosefoot Family}

Atriplex

Atriplex canescens (Pursh) Nutt.

Fourwing saltbrush

var. canescens

[=Calligonum canescens Pursh]

North Crater Flat(UNLV), Chuckwalla Canyon(UNLV), Tarantula Canyon(UNLV), Tates Wash(UNLV), Yucca Mtn. (O\&C, UNLV), Forty-Mile Wash(UNLV), Beatty Wash(UNLV), Solitario Canyon(UNLV), Yucca Mtn. Ridge(UNLV), northeastern base of Yucca Mtn. (UNLV), Meiklejohn 
Mtn. (UNLV), Razorback Ridge(UNLV), Tates Wash(UNLV).

Atriplex confertifolia (Torr. \& Frem.) S. Wats.

Shadscale

$[=$ obione confertifolia Torr. \& Frem. in Frem.;

A. collina woot. \& Standl.]

Steves Pass(UNLV), Black Marble Mtn. (UNLV), Crater Flat (UNLV), Fluorspar Canyon(UNLV), Tates Wash(UNLV), Tarantula Canyon(UNLV), Yucca Mtn. (UNLV-C), Beatty Wash (UNLV), Solitario Canyon(UNLV), canyon north of Wildcat Peak(UNLV), Forty-Mile Wash(UNLV), Busted Butte(UNLV), southern base of Yucca Mtn. (UNLV), Yucca Mtn. Ridge(UNLV), Tates Wash (UNLV-C).

Atriplex elegans

ssp. fasciculata (S. Wats.) Hall \& Clem.

Wheelscale orach [lobione gardneri Moq.;

A. nuttallii Wats.]

South end of Yucca Mtn. (JCB).

Atriplex hymenelytra (Torr.) S. Wats.

Desert-holly

[=obione hymenelytra Torr.]

Beatty Wash(JCB).

Atriplex polycarpa (Torr.) S. Wats.

Forty-Mile Wash(UNLV), Beatty Wash(JCB, UNLV), Solitario Canyon(UNLV), canyon north of wildcat Peak (UNLV), Forty-Mile Wash(UNLV).

Ceratoides

Ceratoides lanata (Pursh) J. T. Howell

Winterfat

[l= Diotis lanata Pursh;

Eurotia lanata (Pursh) Moq.;

Krascheninnikovia lanata (Pursh) Meeuse \& Smit]

Crater Flat(UNLV-C), Fluorspar Canyon(UNLV), Tates Wash(UNLV-C), Tarantula Canyon(UNLV), Chuckwalla Canyon(UNLV), Yucca Mtn. (O\&C, UNLV), Busted Butte(UNLV), Beatty Wash(UNLV), Solitario Canyon(UNLV), canyon north of Wildcat Peak (UNLV), Forty-Mile Wash(UNLV), southern base of Yucca Mtn. (UNLV), Yucca Mtn. Ridge (UNLV), Meiklejohn Mtn. (UNLV), Tates Wash (UNLV).

\section{Chenopodium}

Chenopodium desiccatum

var. Ieptophylloides (Murr) H. A. Wahl

Desert goosefoot

$[=$ C. pratericola Rydb.;

C. petiolare var. leptophylloides Murray;

c. Leptophyllum var. dessicatum (A. Nels.) Aellen;

c. leptophyllum var. oblongifolium S. Wats.;

C. pratericola var. oblongifolium (S. Wats.) Wahl]

North Amargosa Valley (JCB).

Chenopodium fremontii

Fremont's goosefoot

var. incanum $S$. Wats.

[=C. incanum (S. Wats.) A. Heller]

Beatty Wash (JCB) . 
Grayia spinosa (Hook.) Moq.

[=Chenopodium spinosum Hook .;

G. polygaloides H. \& A.]

Chuckwalla Canyon(UNLV), Tarantula Canyon(UNLV), Yucca Mtn. (O\&C, UNLV), Tates Wash(UNLV), Busted Butte(UNLV), Beatty Wash(UNLV), Solitario Canyon(UNLV), Forty-Mile Wash(UNLV-C), Yucca Mtn. Ridge(UNLV), northeastern base of Yucca Mtn. (UNLV), Meiklejohn Mtn. (UNLV), Razorback Ridge(UNLV), Tates Wash (UNLV).

Halogeton

Halogeton glomeratus (Bieb.) C. A. Mey. in Led.

Halogeton

[= Anabasis glomerata (Bieb.) C. A. Mey]

Yucca Mtn. (UNLV).

Rochia

Kochia americana s. Wats.

$[=\underline{\mathrm{K}}$. americana var. vestita (Wats.) Rydb.

Tates Wash(UNLV), Beatty Wash (UNLV-C).

Salsola

Salsola paulsenii Litv.

Russian-thistle

Crater Flat (UNLV), Yucca Mtn. (O\&C, UNLV), Busted Butte (UNLV), Beatty

Wash (UNLV), Solitario Canyon(UNLV), canyon north of Wildcat Peak(UNLV),

Forty-Mile Wash(UNLV), northeastern base of Yucca Mtn. (UNLV).

Crossosomataceae

Glossopetalon

Glossopetalon pungens Brandeg.

[=Forsellesia pungens (Brandeg.) A. A. Heller]

Tarantula Canyon(UNLV-C), Razorback Ridge(UNLV).

Cuscutaceae Dodder Family

\section{Cuscuta}

Cuscuta californica Hook \& Arn.

Specie spring (UNLV-C).

Cuscuta denticulata Engelm.

[ $=$ Grammica denticulata (Engelm.) W. A. Weber]

Small-tooth dodder

Below Bare Mtn. (JCB).

Cuscuta salina Engelm.

Salt dodder

[ =C. californica var. squamigera Engelm.;

c. squamigera (Engelm.) Piper;

Grammica salina (Engelm.) Taylor \& Macbryde;

c. veatchil var, apoda Yuncker;

c. nevadensis Johnston;

C. salina var. apoda Yuncker) Yuncker]

North Amargosa Valley(JCB). 


\section{Euphorbia}

Euphorbia albomarginata Torr. \& Gray

Rattlesnake-weed Crater Flat (JCB, UNLV-C), Specie spring (UNLV), Fluorspar Canyon(UNLVC), Tates Wash (UNLV), Crescent Canyon (UNLV), Tarantula Canyon(UNLV), Yucca Mtn. (UNLV), Forty-Mile Wash(UNLV), Beatty Wash(UNLV), Solitario Canyon(UNLV), northeastern base of Yucca Mtn. (UNLV), Meiklejohn Mtn. (UNLV), Razorback Ridge (UNLV).

Euphorbia Eendleri Torr. \& Gray Busted Butte (UNLV).

Euphorbia micromera Boiss.

[=E. podagrica Johnst . ;

Chamaesyce micromera (Engelm.) Woot. \& Standl.] Crater Flat (JCB).

Euphorbia parishii Greene

[=Chamaesyce parishii (E. Greene) Millsp.]

Below Red Cinder Cone (Crater Flat) (JCB).

Euphorbia setiloba Engelm. in Torr.

[=Chamaesyce setiloba (Torr.) Millsp. ex Parish]

Fringed spurge

Northwest Crater Flat (JCB).

Fabaceae (Leguminosae) Pea Family

\section{Astragalus}

Astragalus acutirostris $\mathrm{S}$. Wats.

Crater Flat (JCB), Yucca Mtn. (UNLV-C), Cresent Cliff(UNLV-C), Yucca Mtn. Ridge (UNLV-C), Razorback Ridge (UNLV).

Astragalus didymocarpus Hook. \& Arn.

var. didymocarpus

Forty-Mile Wash(UNLV-C), Cresent Cliff(UNLV-C).

Astragalus didymocarpus

Two-seeded milkvetch

var. dispermus (Gray) Jeps.

Forty-Mile Wash(UNLV-C), Cresent Cliff(UNLV-C), Specie Spring(UNLV-C), Specie Spring (UNLV-C).

Astragalus funereus M. E. Jones

Black milkvetch Below Northern Yucca Mtn. (JCB), Beatty Wash (UNLV-C) .

Astragalus layneae Greene Specie Spring(UNLV-C), North Bare Mtn. (JCB), Chuckwalla Canyon (UNLV-C), Tates Wash(UNLV), Beatty Wash(UNLV-C), Crater Flat(UNLV), Beatty Wash(UNLV-C), northeastern base of Yucca Mtn. (UNLV), Meiklejohn Mtn. (UNLV), Razorback Ridge (UNLV). 
var. Eremontii (Gray) s. Wats.

$[=\mathrm{A}$. Eremontil Gray ex. Torr.;

A. coulteri var. fremontii (Gray) Jones;

Cystium fremontii (Gray) Rydb.]

Crater Flat (JCB), Tates Wash (UNLV-C), Forty-Mile Wash(UNLV-C).

Astragalus lentiginosus

Shining milkvetch

var. variabilis Barneby

Lower Forty-Mile Wash(UNLV-C), Busted Butte (UNLV-C).

Astragalus nuttallianus

Small-flowered milkvetch

var. imperfectus (Rydb.) Barneby

Chuckwalla Canyon (UNLV-C), Yucca Mtn. (O\&C, UNLV-C), Beatty Wash (UNLV-

C), Yucca Mtn. Ridge (UNLV), northeastern base of Yucca Mtn. (UNLV), Meiklejohn Mtn. (UNLV), Razorback Ridge(UNLV).

Astragalus nyensis Barneby

Beatty Wash (UNLV-C).

Astragalus purshii

Pursh's milkvetch

var. tinctus M. E. Jones

Fluorspar Canyon(UNLV-C), Beatty Wash (UNLV), northeastern base of Yucca Mtn (UNLV), northeastern base of Yucca Mtn. (UNLV-C).

\section{Lathyrus}

Lathyrus hitchcockianus Barneby \& Reveal

Yucca Mtn. (JCB).

Lotus

Lotus humistatus Greene

Low trefoil

Yucca Mtn. (JCB, O\&C, UNLV), Solitario Canyon(UNLV-C), Beatty Wash (UNLV-

C), Yucca Mtn. Ridge (UNLV-C), northeastern base of Yucca Mtn. (UNLV), Specie Spring (UNLV-C).

Lupinus

Lupinus brevicaulis $s$. Wats.

Yucca Mtn. (O\&C), Yucca Mtn. Ridge (UNLV-C), northeastern base of Yucca Mtn. (UNLV), Razorback Ridge (UNLV-C).

Lupinus concinnus

var. orcuttii (S. Wats.) C. P. Sm.

[ =L. micensis Jones;

L. orcuttii S. Wats.;

L. concinnus ssp. orcuttii (S. Wats.) Dunn]

Beatty Wash(JCB, UNLV-C), Cresent Cliff(UNLV-C), Meiklejohn Mtn. (UNLVC), Specie Spring (UNLV-C).

Lupinus Elavoculatus Heller

Yellow-eye lupine

$[=I$. nubens var. flavoculatus (Heller) C.P. Small;

L. ordoratus var. flavoculatus (Heller) Jepson]

Below Northern Bare Mtn. (JCB), Yucca Mtn. (O\&C), Beatty Wash (UNLV-C), Yucca Mtn. Ridge(UNLV-C), northeastern base of Yucca Mtn. (UNLV), 
Meiklejohn Mtn. (UNLV), Razorback Ridge(UNLV) .

Lupinus shockleyi s. Wats.

Forty-Mile Wash(UNLV-C), Beatty Wash(UNLV), Busted Butte (UNLV-C).

\section{Psorothamnus}

Psorothamnus Eremontii (Torr.) Barneby $\quad$ Fremont's indigobush

var. Eremontii

[=Dalea Eremontii Torr. ex Gray;

Parosela Eremontii (Torr.) Vail;

Psorodendron fremontii (Torr.) Rydb.;

Dalea johnsonii s. Wats.;

Parosela johnsonii (s. Wats.) Vail;

Psorodendron johnsonii (S. Wats.) Rydb.;

Parosela johnsonii var. minutiflora Parish;

Dalea Eremontii var. minutifolia (Parish) L. Benson]

Crater Flat(JCB, UNLV), Chuckwalla Canyon(UNLV), Fluorspar

Canyon(UNLV), Tates Wash(UNLV), Crescent Cliff(UNLV), Tarantula

Canyon(UNLV), Busted Butte (UNLV), Beatty Wash (UNLV), southern base of Yucca Mtn. (UNLV), Meiklejohn Mtn. (UNLV), Razorback Ridge(UNLV), Tates Wash (UNLV).

Psorothamnus polydenius (Torr.) Rydb.

Glandular indigobush

[ = Dalea polydenius Torr. ex S. Wats.;

Parosela polydenia (Torr.) Heller]

Forty-Mile Wash(UNLV), Beatty Wash(UNLV-C), Busted Butte (UNLV-C), Tates Wash (UNLV-C) .

Geraniaceae Geranium Family

Erodium

Erodium cicutarium (L.) L'Her.

Storksbill

[= Geranium cicutarium L.]

Chuckwalla Canyon(UNLV), Specie Spring(UNLV), Fluorspar Canyon(UNLV), Crescent Cliff(UNLV), Tarantula Canyon(UNLV), Yucca Mtn. (O\&C, UNLV-C), Beatty Wash(UNLV), Solitario Canyon(UNLV), Forty- Mile Wash(UNLV), Yucca Mtn. Ridge(UNLV), northeastern base of Yucca Mtn. (UNLV), Meiklejohn Mtn. (UNLV), Razorback Ridge(UNLV).

Hydrophyllaceae Waterleaf Family

Emmenanthe

Emmenanthe penduliflora Benth.

Whispering-bells Crescent Cliff(UNLV-C), Fluorspar Canyon(UNLV), Meiklejohn Mtn. (UNLV), Razorback Ridge (UNLV).

Eucrypta

Eucrypta chrysanthemifolia

var. bipinnatifida (Torr.) Const.

Chuckwalla Canyon(UNLV-C), Specie Spring(UNLV). Tarantula Canyon(UNLV), Beatty Wash (UNLV), canyon north of Wildcat Peak (UNLV). 
Eucrypta micrantha (Torr.) Heller

[ Phacelia micrantha Torr;

P.pinetorum M.E. Jones]

Crescent Cliff (UNLV), Razorback Ridge(UNLV).

Nama

Nama aretioides

var. multiflorum (A.A. Heller) Jepson

Forty-Mile Wash (UNLV-C), Beatty Wash(UNLV-C) .

Nama demissum Gray

Purple-mat

var. demissum

[=Conanthus demissus (Gray) Heller;

N. demissum var. deserti Brand]

Red Cinder Cone (Crater Flat) (JCB), Yucca Mtn. (O\&C), Beatty Wash (UNLV), Buarws Vurrw (UNLV-C), Meiklejohn Mtn. (UNLV).

Nama densum Lemmon

Beatty Wash (UNLV-C).

Nama depressum Lemmon ex Gray

Forty-Mile Wash(UNLV-C), Busted Butte(UNLV-C).

Nama pusillum Lemmon ex Gray

Busted Butte (UNLV-C).

Phacelia

Phacelia crenulata Torr.

var. crenulata

[l=P. orbicularis Rydb.;

P. crenulata var. funerea J. Voss]

Crater Flat (UNLV), Tates Wash (UNLV), Solitario Canyon(UNLV-C), Busted Butte(UNLV), Busted Butte (UNLV), southern base of Yucca Mtn. (UNLV-C).

D Phacelia cryptantha Greene

Meiklejohn Mtn. (UNLV-C) .

Phacelia fremontii Torr. in Ives

Crater Flat (JCB, UNLV-C), Yucca Mtn. (O\&C, UNLV-C), Chuckwalla Canyon (UNLV), Beatty Wash(UNLV), Yucca Mtn. Ridge (UNLV), northeastern base of Yucca Mtn. (UNLV), Meiklejohn Mtn. (UNLV), Specie Spring(UNLV-C), Razorback Ridge (UNLV).

Phacelia mustelina Cov.

Death Valley round-leaf Solitario Canyon(UNLV-C), Yucca Mtn. Ridge(UNLV-C), northeastern base of Yucca Mtn. (UNLV), Tates Wash (UNLV-C)..

Phacelia pedicellata Gray

Canyon north of Wildcat Peak (UNLV). 
var. jaegeri Munz

[=P. laxiflora J.T. Howell;

P. perityloides var. laxiflora (J.T. Howell) Cronq.]

Chuckwalla Canyon(UNLV), Tarantula Canyon(UNLV), canyon north of Wildcat Peak (UNLV) .

Phacelia rotundifolia Torr. ex S. Wats.

Limestone phacelia Crater Flat (UNLV-C), North Yucca Mtn. (JCB), Black Marble Mtn. (UNLV), Chuckwalla Canyon(UNLV-C), Beatty Wash(UNLV), Solitario Canyon (UNLV-C), northeastern base of Yucca Mtn. (UNLV-C), Meiklejohn Mtn. (UNLV), Razorback Ridge (UNLV).

Phacelia saxicola Gray

Rock phacelia Solitario Canyon(UNLV-C), Yucca Mtn. Ridge(UNLV-C), Meiklejohn Mtn. (UNLV-C).

Phacelia vallis-mortae J. Voss

Death Valley phacelia

var. vallis-mortae

Crater Flat (JCB), Yucca Mtn. (O\&C, UNLV-C), Beatty Wash (UNLV-C), Yucca Mtn. Ridge (UNLV), northeastern base of Yucca Mtn. (UNLV), northeastern base of Yucca Mtn. (UNLV-C), Meiklejohn Mtn. (UNLV-C), Razorback Ridge (UNLV), Tates Wash (UNLV).

Tricardia

Tricardia watsonii Torr. ex Wats.

Three-hearts Tates Wash(UNLV-C), Tarantula Canyon(UNLV), Cresent Cliff(UNLV-C), Yucca Mtn. Ridge (UNLV).

Krameriaceae Krameria Family

Krameria

Krameria parvifolia Benth.

Range ratany

$[=\underline{\text { K. erecta }}$ Schultes;

E. parvifolia var. imparata J.F. Macbr.;

K. glandulosa Rose \& Painter;

K. imparata (Britt.) Macbr.]

Crater Flat (UNLV), Yucca Mtn. (UNLV-C), Busted Butte (UNLV), Solitario Canyon(UNLV), Forty-Mile Wash(UNLV), southern base of Yucca Mtn. (UNLV), Tates Wash (UNLV).

\section{Lamiaceae (Labiatae) Mint Family}

\section{Monardella}

Monardella odoratissima Benth.

[-Madronella oblongifolia Rydb.; Madronella sessilifolia Rydb.; Monardella parvifolia Greene]

Chuckwalla Canyon(UNLV).

Salazaria

Salazaria mexicana Torr.

Bladder sage 


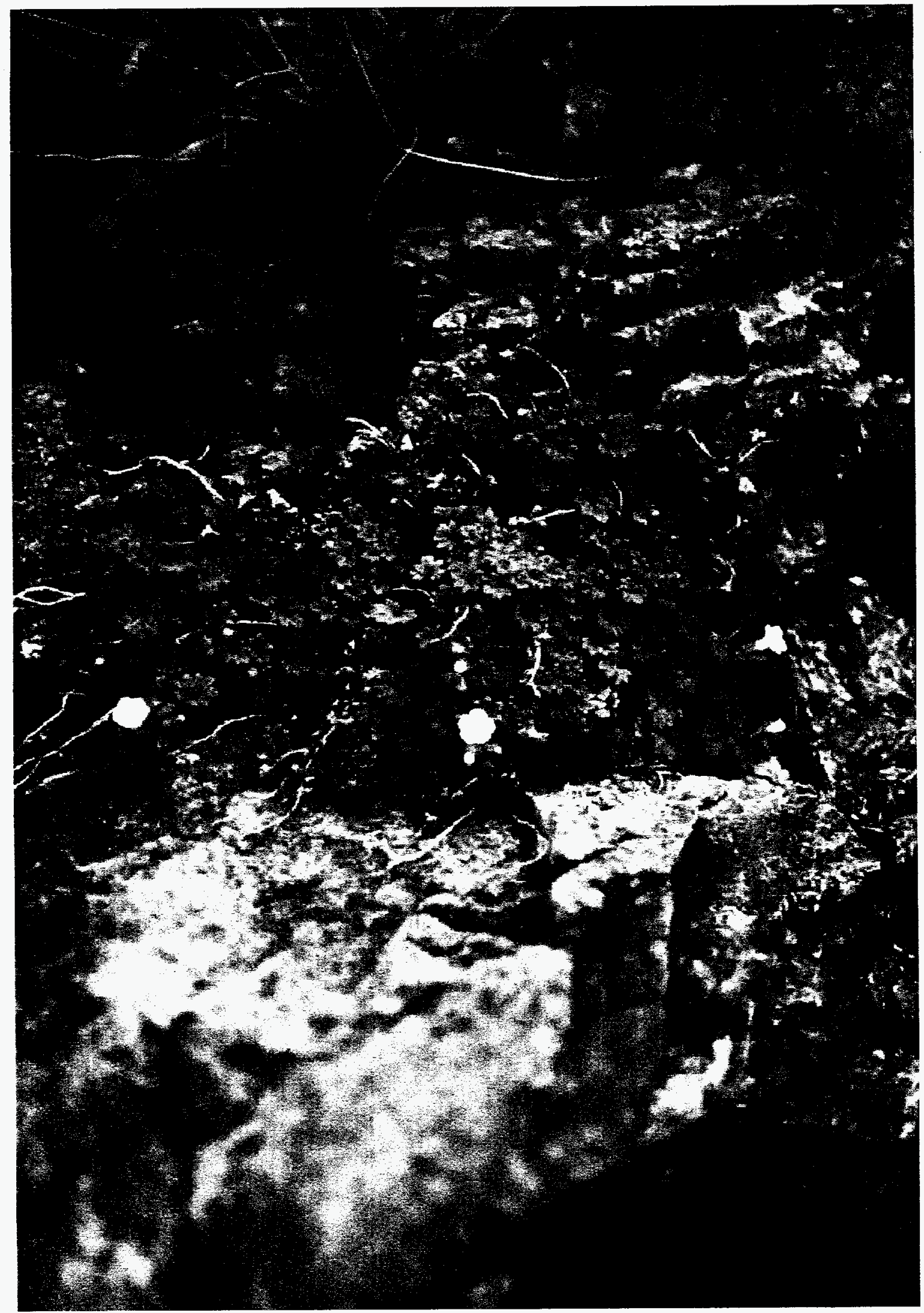

Figure 6. Phacelia perityloides Cov. var. jaegeri Munz. A perennial herb known in the study area only from limestone rock crevices of certain north-facing canyon walls of Bare Mountain. 
Crater Flat(JCB), Chuckwalla Canyon(UNLV), Specie Spring(UNLV), Fluorspar Canyon(UNLV), Tates Wash(UNLV), Crescent Cliff(UNLV), Tarantula Canyon(UNLV), Yucca Mtn. (O\&C, UNLV), Busted Butte(UNLV), Beatty Wash(UNLV-C), Solitario Canyon(UNLV), canyon north of wildcat Peak(UNLV), northeastern base of Yucca Mtn. (UNLV), Meiklejohn Mtn. (UNLV), Tates Wash (UNLV).

Salvia

Salvia columbariae Benth.

Chia var. columbariae Forty-Mile Wash(UNLV), Chuckwalla Canyon(UNLV-C), Beatty Wash(JCB, UNLV-C), Solitario Canyon (UNLV), northeastern base of Yucca Mtn. (UNLV), Meiklejohn Mtn. (UNLV), Specie Spring(UNLV-C), Razorback Ridge(UNLV), Tates Wash (UNLV).

Salvia dorrii (Kell.) Abrams Dorr's sage var. dorrij

I= Audibertia dorrii Kellogg;

Audibertiella argentea Rydb.;

S. pilosa Merriam;

S. carnosa Dougl.;

S. carnosa var. pilosa Jepson;

S. dorrii var. argentea (Epl.) Munz;

s. dorrii var. gilmanii (Epl.) Abrams]

Below North Yucca Mtn. (JCB), Bare Mtn. (JCB), Tates Wash(UNLV), Chuckwalla Canyon(UNLV), canyon north of wildcat Peak(UNLV), Beatty Wash (UNLV-C), Yucca Mtn. Ridge (UNLV-C).

Loasaceae stick-leaf Family

Eucnide

Eucnide urens (Gray) Parry

Pocknettle

[= Mentzelia urens Gray]

Canyon north of Wildcat Peak (UNLV-C).

\section{Mentzelia}

Mentzelia albicaulis Dougl ex Hook

[=Bartonia albicaulis Hook.;

Acrolasia albicaulis (Hook.) Rydb.;

M. albicaulis var. gracilis (Rydb.) Darlington;

M. montana (A. Davidson) A. Davidson;

M. obscura Thompson \& Roberts]

Crater Flat (JCB, UNLV-C), Yucca Mtn. (O\&C), Forty-Mile Wash(UNLV), Beatty Wash(UNLV-C), Busted Butte(UNLV), southern base of Yucca Mtn. (UNLV), Yucca Mtn. Ridge(UNLV), northeastern base of Yucca Mtn. (UNLV-C), Meiklejohn Mtn. (UNLV-C), Specie Spring(UNLV-C), Razorback Ridge (UNLV) .

Mentzelia nitens Greene

Beatty Wash (JCB, UNLV-C).

Mentzelia reflexa Cov. 
West slope of Bare Mtn. (JCB).

Mentzelia veatchiana Kell.

Northeastern base of Yucca Mtn. (UNLV-C).

Petalonyx

Petalonyx nitidus s. Wats.

Sandpaper-plant

[=P. thurberi var. nitidus (S. Wats.) Jones]

Bare Mtn. (JCB), Crater Flat (UNLV), Busted Butte (UNLV), canyon north of

Wildcat Peak (UNLV-C).

Loganiaceae Logania Family

Buddleja

Buddleja utahensis Cov.

Bare Mtn.(JCB), Chuckwalla Canyon(UNLV), Tarantula Canyon(UNLV), Meiklejohn Mtn. (UNLV), Razorback Ridge (UNLV).

Malvaceae Mallow Family

Bremalche

Eremalche exilis (Gray) Greene

[= Malvastrum exile Gray;

Malveopsis exile (Gray) Kuntze;

Eremalche exile (Gray) Greene;

Sphaeralcea exile (Gray) Jepson]

Beatty Wash (JCB), Forty-Mile Wash(UNLV-C).

Malva negecta Wallr.

Beatty Wash (UNLV-C).

Eremalche rotundifolia (Gray) Greene

Desert-fivespot

[=Ma] vastrum rotundifolia Gray]

Near Red Cinder Cone (Crater Flat) (JCB), Forty-Mile Wash(UNLV).

Sphaeralcea

Sphaeralcea ambigua Gray

Apricot-mallow, globe-mallow

ssp. ambigua

[=S. ambigua var. monticola Kearney]

Black Marble Mtn. (UNLV), Chuckwalla Canyon(UNLV), Tarantula Canyon(UNLV), Specie Spring(UNLV), Fluorspar Canyon(UNLV), Tates Wash(UNLV), Crescent Cliff(UNLV), Yucca Mtn. (O\&C, UNLV-C), Busted Butte(UNLV), Beatty Wash(UNLV), Solitario Canyon(UNLV), canyon north of Wildcat Peak(UNLV), Forty-Mile Wash(UNLV), Yucca Mtn. Ridge(UNLV), northeastern base of Yucca Mtn. (UNLV), Meiklejohn Mtn. (UNLV), Tates Wash (UNLV).

Nyctaginaceae Four O'Clock Family

\section{Abronia}

Abronia turbinata S. Wats.

Sand-verbena Lower Forty-Mile Wash(UNLV-C), Busted Butte(UNLV-C), northeastern base 
of Yucca Mtn. (UNLV).

Mirabilis

Mirabilis bigelovij Gray

var. bigelovii

$[=\underline{M}$. bigelovii var. aspera (E. Greene) Munz]

Crater Flat (UNLV), Chuckwalla Canyon(UNLV), Tates Wash(UNLV), Tarantula

Canyon(UNLV), Yucca Mtn(O\&C, UNLV), Beatty Wash(JCB, UNLV-C), Solitario

Canyon(UNLV), canyon north of Wildcat Peak(UNLV), southern base of

Yucca Mtn. (UNLV), Yucca Mtn. Ridge (UNLV), northeastern baase of Yucca

Mtn. (UNLV), Meiklejohn Mtn. UNLV), Razorback Ridge(UNLV) .

Mirabilis froebelii (Behr) Greene

$[=\underline{M}$. multiflora var. pubescens $S$. Wats.;

M. Eroebellii (Behr.) Greene;

M. Eroebellii var. glabrata (Standl.) Jepson]

Bare Mtn. (JCB), Fluorspar Canyon(UNLV), Meiklejohn Mtn. (UNLV).

Selinocarpus nevadensis Fowler \& B. Turner

Southern base of Yucca Mtn. (UNLV-C)

Oleaceae Olive Family

Forestiera

Forestiera pubescens Nutt.

Coyote-bush

$[=E$. neomexicana Gray;

Adelia neomexicana (Gray) Kuntze;

A. parvifolia Cov.]

Specie Spring (UNLV-C) .

Fraxinus

Eraxinus anomala Torr. ex Wats.

Singleleaf ash

Tarantula Canyon(UNLV), Chuckwalla Canyon(UNLV-C), Tates Wash(UNLV).

Eraxinus velutina Torr.

Velvet ash

[=F. velutina var. coriacea (S. Wats.) Rehder]

Chuckwalla Canyon (UNLV-C) .

Menodora

Menodora spinescens Gray

Crater Flat (JCB, UNLV-C), Fluorspar Canyon(UNLV), Tates Wash(UNLV), Yucca Mtn. (O\&C, UNLV-C), Busted Butte(UNLV), Forty-Mile Wash(UNLV), Beatty Wash(UNLV), Solitario Canyon(UNLV), northeastern base of Yucca Mtn. (UNLV), Tates Wash (UNLV).

\section{Onagraceae Evening-primrose Family}

\section{Camissonia}

Camissonia boothii

ssp. condensata (Munz) Raven

[ =enothera decorticans var. condensata Munz;

C. boothii ssp. condensata (Munz) Raven] 


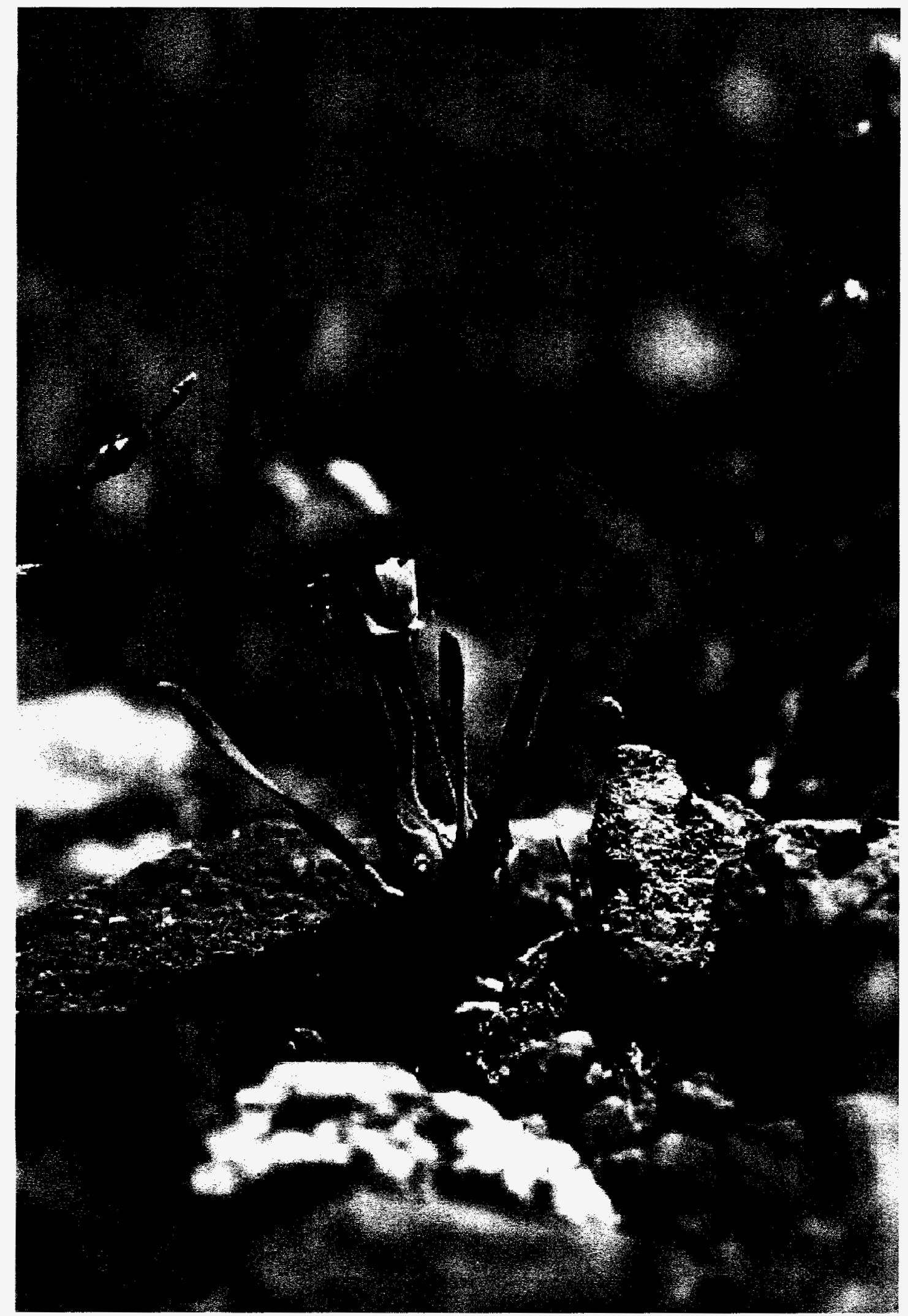

Figure 7. Camissonia palmeri (S. Wats.) Raven. A dwarf (2-6 cm high) annual, reported for the first time in the study area from the ridge and northeastern base of Yucca Mountain. 
Yucca Mtn. (O\&C, JCB), Bare Mtn. (JCB), Busted Butte (UNLV-C) .

Camissonia boothii

ssp. intermedia (Munz) Raven

Beatty Wash (UNLV-C).

Camissonia brevipes (Gray) Raven

ssp. brevipes

[

Chylismia brevipes (Gray) Small]

Crater Flat (JCB), Beatty Wash(UNLV), Yucca Mtn. (O\&C), southern base of Yucca Mtn. (UNLV), northeastern base of Yucca Mtn. (UNLV), Meiklejohn Mtn. (UNLV-C), Razorback Ridge(UNLV) .

Camissonia brevipes

ssp. paliidula (Munz) Raven

[ $=$ Denothera brevipes var. pallidula Munz]

North Amargosa Valley(JCB).

Camissonia chamaenerioides (Gray) Raven

Meiklejohn Mtn. (UNLV-C).

Camissonia claviformis

ssp. integrior (Raven) Raven

[ = Denothera claviformis Torr. \& Frem. in Frem.;

o. scapoidea var. claviformis (Torr. \& Frem.) S. Wats.;

Chylismia claviformis (Torr. \& Frem.) Heller]

North Amargosa Valley (Beatty Wash) (JCB), Forty-Mile Wash(UNLV-C), Busted Butte (UNLV).

Camissonia heterochroma (S. Wats.) Raven

Shockley's evening-primrose [

North Amargosa Valley(JCB), Below Yucca Mtn. (JCB), Beatty Wash (UNLV), Tates Wash (UNLV-C).

Camissonia kernensis (Munz) Raven

ssp. gilmanii (Munz) Raven

[= Denothera kernensis var. gilmanii (Munz) Munz]

Beatty Wash(UNLV-C), northeastern base of Yucca Mtn. (UNLV-C).

Camissonia palmeri (S. Wats.) Raven

[= Denothera pa]meri $\mathrm{s}$. Wats;

Taraxia palmeri Small]

Yucca Mtn. Ridge (UNLV-C), northeastern base of Yucca Mtn. (UNLV-C).

Camissonia parvula (Torr. \& Gray) Raven

[= Oenothera parvula Torr. \& Gray;

ㅇ․ contorta Douglas var. Elexuosa (Nelson) Munz]

Forty-Mile Wash(UNLV-C), Beatty Wash (UNLV-C).

Camissonia pterosperma (S. Wats.) Raven

[=Oenothra pterosperma $S$. Wats.] 
Meiklejoh Mtn. (UNLV-C).

Camissonia refracta ( $S$. Wats.) Raven

[= Denothera refracta $\mathrm{S}$. Wats.]

Bare Mtn. (JCB), Meiklejohn Mtn. (UNLV-C).

Camissonia walkeri

ssp. tortilis (Jepson) Raven

$[=$ Oenothera brevipes var. parviflora $\mathrm{S}$. Wats.;

Denothera walkeri (A. Nels.) Raven;

Chylisma walkeri A. Nels.;

Denothera scapoidea var. tortilis Jepson;

Camissonia walkeri ssp. tortilis (Jepson) Raven;

oenothera multijuga var. orientalis Munz]

North Bare Mtn. (JCB), Busted Butte(UNLV), canyon north of Wildcat

Peak (UNLV), Busted Butte(UNLV-C).

\section{Oenothera}

Oenothera caespitosa

ssp. marginata (Nutt.) Munz

[=0enothera montana Nutt. in Torr. \& Gray;

Denothera marginata var. purpurea $\mathrm{S}$. Wats.;

Pachylophus canescens Piper]

Specie Spring(UNLV), Tates Wash(UNLV), Yucca Mtn. (UNLV), Beatty Wash(JCB), northeastern base of Yucca Mtn. (UNLV), Meiklejohn Mtn. (UNLV).

Denothera deltoides Torr. \& Frem. Basket evening-primrose, dune-primrose ssp. deltoides

[=Anogra deltoides (Torr. \& Frem.) Small]

West Jackass Flats (JCB), Yucca Mtn. (O\&C).

Orobanchaceae Broom-rape Family

\section{Orobanche}

Orobanche ludoviciana

var. cooperi (Gray) Beck

[=Aphylion cooperi Gray;

o. cooperi (Gray) Heller]

Chuckwalla Canyon (UNLV).

Papaveraceae Poppy Family

\section{Eschscholzia}

Eschscholzia glyptosperma Greene

Mojave-poppy

Beatty Wash(UNLV), Crater Flat(UNLV, Forty-Mile Wash(UNLV), southern base of Yucca Mtn. (UNLV)

Eschscholzia minutiflora S. Wats.

$[=E$. minutiflora var. covillei (Greene) C. Clark;

E. minutiflora var. twisselmannii C. Clark]

Tates Wash(UNLV-C), Yucca Mtn. (JCB, UNLV), Forty-Mile Wash(UNLV), 
Chuckwalla Canyon(UNLV), Beatty Wash(UNLV-C), Solitario Canyon (UNLV), southern base of Yucca Mtn. (UNLV), northeastern base of Yucca Mtn. (UNLV), Meiklejohn Mtn. (UNLV), Razorback Ridge(UNLV).

Plantaginaceae Plantain Family

Plantago

Plantago insularis

var. fastigiata (Morris) Jeps.

$[=$ P. Eastigiata Morris;

P. ovata Forsskal]

Bare Mtn. (JCB), Yucca Mtn. (JCB), Busted Butte(UNLV), southern base of Yucca Mtn. (UNLV).

Plantago purshii

var. oblonga (M.E. Jones) Shinners

[l= p. patagonica Jacq.]

Specie spring (UNLV-C).

Polemoniaceas phlox Family

Eriastrum

Eriastrum eremicum (Jeps.) Mason

[= Huegelia eremica Jepson]

Yucca Mtn. (O\&C, UNLV), Solitario Canyon(UNLV-C), Beatty Wash(UNLV), Forty-Mile Wash(UNLV), Yucca Mtn. Ridge(UNLV), Meiklejohn Mtn. (UNLV), Razorback Ridge (UNLV).

Eriastrum wilcoxii (A. Nels.) Mason

Yucca Mtn. $(O \& C)$.

Gilia

Gilia campanulata Gray

South Forty-Mile Wash(JCB), Beatty Wash(UNLV-C), Busted Butte(UNLV-

C).

Gilia Eiliformis Parry ex Gray

Meiklejohn Mtn. (UNLV-C).

Gilia hutchinsifolia Rydb.

[=G. Ieptomeria ssp. rubella (Brand) Mason \& Grant]

North Amargosa Valley, (and between Bare Mtn. and Yucca Mtn.) (JCB).

Gilia inconspicua (J.E. Smith) Sweet

[=Ipomopsis inconspicua J.E. Smith;

Gilia sinuata Dougl. ex Benth.;

G. ophthalmeides Brand;

G. brecciarum M.E. Jones;

G. Clokeyi H. Mason \& A. Grant;

G. transmontana (Mason \& A. Grant) A. \& V. Grant;

G. aliquanta A. \& V. Grant;

G. malior Day \& V. Grant] 
Below northwest Yucca Mtn(JCB), Beatty Wash (JCB, UNLV), Fluorspar Canyon(JCB), Crater Flat (UNLV-C), Crescent Cliff(UNLV-C), Forty-Mile Wash(UNLV-C), Yucca Mtn. Ridge(UNLV), Meiklejohn Mtn. (UNLV), Razorback Ridge (UNLV).

Gilia latiflora (Gray) Gray var. triceps (Brand) Cronq.

[= Gilia cana var. triceps A. \& V. Grant;

Gilia cana var. speciformis A. \& V. Grant]

Areas of Yucca Mtn. and East face of Bare Mtn. (JCB), Beatty Wash(JCB, UNLV-C), Tungsten Canyon(JCB), Red Cinder Cone (Crater Flat) (JCB); Forty-Mile Wash(UNLV-C), Cresent Cliff(UNLV-C), Busted Butte(UNLV), Yucca Mtn. Ridge(UNLV), northeastern base of Yucca Mtn. (UNLV), Meiklejohn Mtn. (UNLV-C), Razorback Ridge(UNLV) .

Gilia latifolia $S$. Wats.

Spring gilia Bare Mtn. (JCB), Chuckwalla Canyon(UNLV-C), southern base of Yucca Mtn. (UNLV-C) .

Gilia leptomeria Gray

Below nw. Yucca Mtn. (JCB), Forty-Mile Wash(UNLV-C), Beatty Wash (UNLVC), northeastern base of Yucca Mtn. (UNLV).

Gilia ripleyi Barneby

Canyon north of Wildcat Peak (UNLV-C).

Ripley's gilia

Gilia scopulorum M. E. Jones

[=G. scopulorum var. deformis Brand]

Bare Mtn. (JCB), Busted Butte (UNLV).

Gilia stellata Heller

Star gilia

Beatty Wash (UNLV).

Ipomopsis

Ipomopsis polycladon (Torr.) V. Grant

[=Gilia polycladon Torr.]

North Amargosa Valley (JCB), Yucca Mtn. (O\&C), Beatty Wash(UNLV-C), northeastern base of Yucca Mtn. (UNLV), Meiklejohn Mtn. (UNLV-C).

\section{Langloisia}

Langloisia schottii (Torr.) Greene

[= Navarretia schottii Torr. in Emory]

Northern Amargosa Valley (Beatty Wash) (JCB, UNLV), below Red Cinder Cone (Crater Flat) (JCB,), Yucca Mtn. (O\&C), Forty-Mile Wash(UNLV),

Busted Butte (UNLV), Tates Wash(UNLV).

Langloisia setosissima (Torr. \& Gray) Greene

[=Navarretia setosissima Torr. \& Gray ex Torr. in Ives]

Scattered areas of North Amargosa Valley(JCB), Southwest Crater

Flat (JCB), Beatty Wash(UNLV-C), Razorback Ridge(UNLV).

Ieptodactylon 
Leptodactylon pungens (Torr.) Rydb.

$[=I$. pungens ssp. hallii (Parish) Mason;

L. pungens ssp. hookeri (Douglas) Wherry;

L. pungens ssp. pulchriflorum (Brand) H. Mason]

Bare Mtn. (JCB), Chuckwalla Canyon(UNLV), Tarantula Canyon(UNLV), Fluorspar Canyon(UNLV), Tates Wash(UNLV), Crescent Cliff(UNLV), Yucca Mtn. (UNLV-C), Busted Butte (UNLV), Beatty Wash (UNLV-C), canyon north of Wildcat Peak(UNLV), northeastern base of Yucca Mtn. (UNLV), Meiklejohn Mtn. (UNLV), Razorback Ridge(UNLV), Tates Wash(UNLV).

\section{Iinanthus}

Linanthus arenicola (M.E. Jones) Jepson \& Bailey Forty-Mile Wash(UNLV-C), Beatty Wash(UNLV-C).

Linanthus bigelovi (Gray) Greene Yucca Mtn. $(O \& C)$, Forty-Mile Wash(UNLV-C), Busted Butte(UNLV), Meiklejohn Mtn. (UNLV).

Linanthus demissus (Gray) Greene Yucca Mtn. (O\&C), Forty-Mile Wash(UNLV), Beatty Wash(UNLV), Yucca Mtn. Ridge (UNLV), Razorback Ridge(UNLV).

Linanthus dichotomus Benth. West Crater Flat(JCB), Cresent Cliff(UNLV-C), Beatty Wash(UNLV-C), Yucca Mtn. Ridge (UNLV-C).

Linanthus jonesii (Gray) Greene Below Bare Mtn. (SW Crater Flat) (JCB, UNLV-C), Chuckwalla Canyon (UNLV) .

Phlox

Phlox longifolia Nutt.

[=Phlox stansburyi (Torr.) Heller;

Longleaf phlox

P. speciosa var. stansburyi Torr. in Emory;

P. longifolia var. stansburyi (Torr.) Gray;

P. longifolia var. brevifolia (Gray) Gray;

P. grahamii wherry]

Below North Bare Mtn. (JCB), Specie Spring(UNLV-C), Fluorspar Canyon(UNLV), Crescent Cliff(UNLV), Yucca Mtn. (JCB, UNLV), Beatty Wash(UNLV-C), northeastern base of Yucca Mtn. (UNLV-C), Razorback Ridge (UNLV) .

\section{Polygonaceae Buckwheat Family}

\section{Chorizanthe}

Chorizanthe brevicornu Torr.

Brittle spineflower

var. brevicornu

Chuckwalla Canyon(UNLV), Solitario Canyon(UNLV), Yucca Mtn. (O\&C), Forty-Mile Wash(UNLV), Beatty Wash(UNLV), Busted Butte(UNLV), southern base of Yucca Mtn. (UNLV), northeastern base of Yucca Mtn. (UNLV), Meiklejohn Mtn. (UNLV), Razorback Ridge(UNLV). 
[= Acanthogonum rigidum Torr.]

Black Marble Mtn. (UNLV), Yucca Mtn. (O\&C, UNLV), Busted Butte (UNLV), Beatty Wash(UNLV), Crater Flat(UNLV), Forty-Mile Wash(UNLV), northeastern base of Yucca Mtn. (UNLV), Meiklejohn Mtn. (UNLV).

Chorizanthe thurberi (Gray) S. Wats.

Thurber's spineflower [= Centrostegia thurberi Gray]

West Crater Flat(JCB), Beatty Wash(UNLV-C), Yucca Mtn. (O\&C), FortyMile Wash(UNLV), Beatty Wash(UNLV), Busted Butte(UNLV), northeastern base of Yucca Mtn. (UNLV), Meiklejohn Mtn. (UNLV), Razorback Ridge (UNLV).

Chorizanthe watsonii Torr. \& Gray

Watson's spineflower Beatty Wash (UNLV-C) .

\section{Eriogonum}

Eriogonum brachypodum Torr. \& Gray

Parry's buckwheat

[ $=$ E. parryi Gray;

E. deflexum ssp. parryi (Gray) S. Stokes;

E. deflexum var. brachypodium (T.\& G.) S. Stokes]

Bare Mtn. (JCB), Chuckwalla Canyon(UNLV-C), northeastern base of Yucca Mtn. (UNLV-C), Meiklejohn Mtn. (UNLV), Razorback Ridge(UNLV), Specie Spring (UNLV-C) .

Eriogonum deflexum Torr. in Ives

[ $=\underline{E}$. deflexum var. nevadense Reveal]

North Amargosa Valley(JCB), Northwest Crater Flat(JCB), Tarantula Canyon(UNLV), Yucca Mtn. (O\&C, UNLV), Busted Butte(UNLV), Forty-Mile Wash(UNLV), Beatty Wash(UNLV), Tates Wash(UNLV).

Eriogonum fasciculatum

var. polifolium (Benth. in DC.) Torr. \& Gray

Mojave buckwheat

[=E. polifolium Benth. in DC.]

Black Marble Mtn(UNLV), Crater Flat (UNLV), Chuckwalla Canyon(UNLV), Specie Spring(UNLV), Tates Wash (UNLV), Crescent Cliff(UNLV), Tarantula Canyon (UNLV), Yucca Mtn. (O\&C,UNLV-C), Busted Butte(UNLV), Beatty Wash(UNLV-C), Solitario Canyon(UNLV), canyon north of Wildcat Peak (UNLV), southern base of Yucca Mtn. (UNLV), Yucca Mtn. Ridge (UNLV), northeastern base of Yucca Mtn. (UNLV), Meiklejohn Mtn. (UNLV), Razorback Ridge (UNLV), Tates Wash (UNLV).

Eriogonum glandulosum (Nutt.) Nutt. ex Benth.

[l=E. carneum (J. Howell) Reveal]

Canyon north of Wildcat Peak (UNLV).

Eriogonum heermannii

Heermann's buckwheat

var. humilius (S. Stokes) Reveal

Chuckwalla Canyon(UNLV), Tarantula Canyon(UNLV), Beatty Wash(UNLV), canyon north of Wildcat Peak(UNLV), Meiklejohn Mtn. (UNLV), Razorback Ridge (UNLV).

Eriogonum inflatum Torr. \& Frem.

Desert-trumpet 
Steves Pass(UNLV), Crater Flat (UNLV), Chuckwalla Canyon(UNLV), Specie Spring(UNLV), Tates Wash(UNLV), Tarantula Canyon(UNLV), Yucca Mtn. (O\&C, UNLV-C), Busted Butte(UNLV), Beatty Wash(UNLV), Solitario Canyon(UNLV), canyon north of Wildcat Peak(UNLV), Forty-Mile Wash (UNLV), southern base of Yucca Mtn. (UNLV), northeastern base of Yucca Mtn. (UNLV), Meiklejohn Mtn. (UNLV), Razorback Ridge (UNLV), Tates Wash (UNLV).

Eriogonum maculatum Heller

[=E. angulosum var. maculatum (Heller) Jepson;

E. angulosum ssp. maculatum (Heller) S. Stokes]

Black Marble Mtn. (UNLV), Chuckwalla Canyon(UNLV-C), Yucca

Mtn. $(O \& C)$, Forty-Mile Wash(UNLV-C), Beatty Wash(UNLV), Busted Butte(UNLV), southern base of Yucca Mtn. (UNLV-C), Yucca Mtn. Ridge (UNLV), Meiklejohn Mtn. (UNLV), Razorback Ridge(UNLV) .

Eriogonum microthecum

Slender buckwheat

var. Eoliosum (Torr. \& Gray) Reveal

$[=E$. effusum var. foliosum Torr. \& Gray;

E. simpsonij Benth in DC.;

E. Eriscanum Jones]

Bare Mtn. (JCB), Fluorspar Canyon(UNLV), Tates Wash(UNLV), Tarantula Canyon(UNLV), Chuckwalla Canyon(UNLV), Yucca Mtn. (UNLV), Beatty Wash(UNLV), northeastern base of Yucca Mtn. (UNLV), Meiklejohn Mtn. (UNLV), Razorback Ridge(UNLV), Tates Wash(UNLV-C) .

Eriogonum nidularium Cov.

Birdnest buckwheat

Fluorspar Canyon(UNLV), Tates Wash(UNLV), Yucca Mtn. (UNLV), Busted Butte(UNLV), Beatty Wash(UNLV-C), Solitario Canyon(UNLV-C), canyon north of Wildcat Peak(UNLV), Forty-Mile Wash(UNLV), Yucca Mtn. Ridge (UNLV), northeastern base of Yucca Mtn. (UNLV), Meiklejohn Mtn. (UNLV-C), Razorback Ridge(UNLV), Tates Wash (UNLV-C).

Eriogonum pusillum Torr. \& Gray

Low buckwheat

$[=E$. reniforme ssp. pusillum (Torr. \& Gray) S. Stokes]

Beatty Wash (JCB, UNLV-C), Solitario Canyon(UNLV-C), Yucca

Mtn. (O\&C), Forty-Mile Wash (UNLV-C), Busted Butte(UNLV), northeastern base of Yucca Mtn. (UNLV), Razorback Ridge(UNLV).

Eriogonum reniforme Torr. \& Frem.

Northwest Amargosa Valley, Beatty Wash(JCB), southern base of Yucca Mtn. (UNLV-C).

Eriogonum rixfordii S. Stokes

Rixford's buckwheat Tates Wash(UNLV), Busted Butte(UNLV), canyon north of Wildcat Peak (UNLV), Beatty Wash(UNLV), Meiklejohn Mtn. (UNLV), Tates Wash(UNLVC).

Eriogonum saxatile $\mathrm{S}$. Wats.

Yucca Mtn. (JCB), northeastern base of Yucca Mtn. (UNLV-C) .

Exiogonum thomasii Torr.

Thomas' buckwheat 
[=E. minutiflorum S. Wats.]

Bare Mtn. (JCB).

Eriogonum trichopes Torr.

Slender-stipe buckwheat

$[=E$. trichopodum Torr. in .DC.;

E. trichopodum var. minus Benth. in DC.]

Bare Mtn. (JCB), Steves Pass(UNLV), Black Marble Canyon(UNLV), Crater Flat (UNLV), Chuckwalla Canyon(UNLV), Yucca Mtn. (UNLV), southern base of Yucca Mtn. (UNLV).

Eriogonum wrightii Torr. in DC.

Wright's buckwheat

Specie Spring(UNLV-C), Tates Wash(UNLV), Razorback Ridge(UNLV).

Oxytheca

Oxytheca perfoliata Torr. \& Gray

[Eriogonum perfoliatum (Torr. \& Gray) S. Stokes]

Fluorspar Canyon(UNLV), Tates Wash(UNLV), Yucca Mtn. (O\&C, UNLV), Beatty

Wash(UNLV), Solitario Canyon(UNLV), Forty-Mile Wash(UNLV), Busted Butte (UNLV), Yucca Mtn. Ridge(UNLV), northeastern base of Yucca Mtn. (UNLV), Meiklejohn Mtn. (UNLV), Razorback Ridge (UNLV), Tates Wash(UNLV).

Portulacaceae purselane Family

\section{Callandrinia}

D Callandrinia ciliata (R. \& P.) DC.

Red-maids

[=C. ciliata var. menziesii (Hook.) Macbr.;

C. ciliata var. micrantha schldl.]

Crescent Cliff (UNLV-C).

\section{Calyptridium}

Calyotridium monandrum Nutt. in Torr. \& Gray

Below Red Cinder Cone (Crater Flat) (JCB), Busted Butte (UNLV-C).

Montia

Montia perfoliata

Miners-lettuce

var. utahensis (Rydb.) Munz

[=Claytonia perfoliata Donn]

Specie Spring(UNLV-C), Crescent Cliff(UNLV-C), Tarantula Canyon (UNLV), Chuckwalla Canyon(UNLV), Yucca Mtn. (JCB, UNLV), Beatty Wash(UNLV-C), Razorback Ridge (UNLV).

Ranunculaceae Crowfoot Family

Anemone

Anemone tuberosa Rydb.

Desert anemone Chuckwalla Canyon(UNLV-C), Tates Wash(UNLV), Crescent Cliff(UNLV), Tarantula Canyon(UNLV), Beatty Wash(UNLV).

Delphinium

Delphinium parishii Gray

Desert larkspur

var. parishii 
Crater Flat(JCB), Chuckwalla Canyon(UNLV), Fluorspar Canyon(UNLV), Tates Wash (UNLV), Tarantula Canyon(UNLV), Yucca Mtn. (O\&C, UNLV), FortyMile Wash(UNLV), Beatty Wash(UNLV), southern base of Yucca Mtn. (UNLV), Yucca Mtn. Ridge(UNLV), northeastern base of Yucca Mtn. (UNLV), Meiklejohn Mtn. (UNLV), Razorback Ridge(UNLV), Tates Wash(UNLV).

\section{Myosurus}

Myosurus cupulatus s. Wats.

Mouse-tail

Specie Spring (UNLV-C).

\section{Ranunculus}

Ranunculus andersonii Gray

Violet buttercup

var. andersonit

$[=\mathrm{R}$. andersonii var. tenellus $\mathrm{s}$. Wats.]

Tarantula Canyon(UNLV-C), Cresent Cliff(UNLV-C

\section{Amelanchier}

Rosaceae Rose Family

Amelanchier utahensis Koehne

Tates Wash (UNLV).

Service-berry

\section{Cercocarpus}

Cercocarpus intricatus $S$. Wats.

Dwarf mountain-mahogany

$[=\underline{C}$. ledifolius var. intricatus (S. Wats.) M.E. Jones;

c. intricatus var. villosus schneider;

C. arizonicus M.E. Jones]

Tarantula Canyon (UNLV-C) .

Coleogye

Blackbrush

Coleogyne ramosissima Torr.

Chuckwalla Canyon, (UNLV) Specie Spring(UNLV), Fluorspar Canyon(UNLV), Tates Wash(UNLV), Crescent Cliff(UNLV), Tarantula Canyon(UNLV), Busted Butte (UNLV), Beatty Wash (UNLV), northeastern base of Yucca Mtn. (UNLV), Meiklejohn Mtn. (UNLV), Razorback Ridge(UNLV), Tates Wash(UNLV) .

Fallugia

Fallugia paradoxa (D. Donn) Endl.

Apache-plume

[=sieversia paradoxa D. Don]

Tarantula Canyon(UNLV).

\section{Petrophytum}

Petrophytum caespitosum (Nutt.) Rydb.

Rock-mat, rock spiraea

[ Spiraea caespitosa Nutt. in Torr. \& Gray;

Eriogyna caespitosa (Nutt.) S. Wats.;

Luetkea caespitosa (Nutt.) Kuntze)

Tarantula Canyon(UNLV), Chuckwalla Canyon(UNLV), Razorback Ridge(UNLV).

Prunus

Prunus Easciculata (Torr.) Gray

Desert-almond

[=Emplectocladus fasciculatus Torr.]

Crater Flat(JCB), Chuckwalla Canyon(UNLV-C), specie spring(UNLV), Crescent Cliff(UNLV), Yucca Mtn. (UNLV), canyon north of wildcat 
Peak(UNLV), Beatty Wash(UNLV), Meiklejohn Mtn. (UNLV), Razorback Ridge (UNLV), Tates Wash (UNLV).

Purshia

Purshia tridentata

var. glandulosa (Curran) M.E. Jones

Antelope-bush, bitterbrush

[= Rurshia glandulosa Curran]

Specie Spring(UNLV-C), Fluorspar Canyon(JCB, UNLV), Tates Wash(UNLV), Crescent Cliff(UNLV), Tarantula Canyon(UNLV), Chuckwalla Canyon(UNLV), Beatty Wash(UNLV-C), Forty-Mile Wash(UNLV), northeastern base of Yucca Mtn. (UNLV), Razorback Ridge (UNLV).

Purshia mexicana (D. Don) Welsh

[=Cowania mexicana var. Stansburiana (Torr.) Jepson]

Cliff-rose

Bare Mtn. (JCB), Chuckwalla Canyon(UNLV), Specie Spring(UNLV), Beatty Wash(UNLV), Meiklejohn Mtn. (UNLV), Razorback Ridge (UNLV), Tates Wash (UNLV).

Rubiaceae Madder Family

Galium

Galium stellatum Kell.

Black Marble Mtn. (UNLV-C), canyon north of Wildcat Peak(UNLV-C), northeastern base of Yucca Mtn. (UNLV).

Salicaceae Willow Family

SaIix

Salix lasiolepis Benth.

Arroyo willow

var. lasiolepis

Specie Spring (UNLV-C).

Saxifragaceae Saxifrage Family

Fendlexella

Fendlerella utahensis (S. Wats.) Heller

Utah fendlerella

[=Whipplea utahensis S. Wats.]

Tarantula Canyon(UNLV-C), Chuckwalla Canyon(UNLV-C), Meiklejohn Mtn. (UNLV-C), Razorback Ridge (UNLV).

Ribes velutinum Greene

Desert gooseberry

var. velutinum

Tarantula Canyon(UNLV), Chuckwalla Canyon(UNLV-C) .

scrophulariaceae Figwort Family

Antirchinum

Antirchinum filipes Gray

[= Neogaerrhinum Eilipes (Gray) Rothm.]

Twining snapdragon

Bare Mtn. (JCB).

Castilleja 
Castilleja chromosa A. Nels.

$[=\underline{C}$. collina $A$. Nels.;

C. angustifolia (Nutt.) D. Don;

C. martinii ssp. ewanii (Eastw.) Munz]

Chuckwalla Canyon(UNLV-C), Specie Spring(UNLV-C), Tates Wash(UNLV), Fluorspar Canyon(JCB, UNLV), Tarantula Canyon(UNLV), Yucca Mtn. (O\&C, UNLV), Beatty Wash (JCB, UNLV), Solitario Canyon(UNLV), northeastern base of Yucca Mtn. (UNLV), Meiklejohn Mtn. (UNLV), Razorback Ridge (UNLV).

Collinsia

Collinsia parviflora Dougl. ex Lindl.

Northeastern base of Yucca Mtn. (UNLV-C).

Mimulus

Mimulus bigelovii

var. cuspidatus A. L. Grant

Monkey-flower

[=M. bigelovi var. panamintensis Munz;

M. spissus A. L. Grant]

Beatty Wash(UNLV-C), Meiklejohn Mtn. (UNLV-C), Razorback Ridge(UNLV), Tates Wash (UNLV).

Mimulus guttatus Fisch. ex DC.

Common monkey-flower

var. guttatus

[=M. glabratus var. fremontii A. L. Grant;

M. glabratus var. Ltahensis Pennell]

Specie Spring (UNLV).

Mimulus parryi Gray

Beatty Wash (UNLV-C) .

Monkey-flower

Mimulus rubellus Gray

Yucca Mtn. (O\&C), Meiklejohn Mtn. (UNLV-C).

Monkey-flower

Mohavea

Mohavea breviflora Cov.

Bare Mtn. (JCB).

Penstemon

Penstemon floridus

ssp. austinil (Eastw.) Keck

Forty-Mile Wash(UNLV-C), Chuckwalla Canyon(UNLV-C), Beatty Wash (UNLVC), northeastern base of Yucca Mtn. (UNLV-C), Meiklejohn Mtn. (UNLV-C), Specie Spring(UNLV), Razorback Ridge(UNLV-C).

Veronica

Veronica anagallis-aquatica L.

Water speedwell

Specie Spring (UNLV-C).

solanaceae Nightshade Family

Datura 
Datura meteloides A. DC. Indian-apple, Jimson-weed, thorn-apple [ $=$ D. wrightii Regel]

Forty-Mile Wash(UNLV).

Lycium

Lycium andersonii Gray

[=L. andersonii var. deserticola (C. Hitchc.) Jepson]

Black Marble Mtn. (UNLV), Crater Flat(UNLV), Fluorspar Canyon(UNLV),

Tates Wash(UNLV-C), Tarantula Canyon(UNLV), Chuckwalla Canyon(UNLV),

Yucca Mtn. (O\&C, UNLV), Busted Butte(UNLV), Beatty Wash(UNLV), Solitario

Canyon(UNLV), canyon north of Wildcat Peak (UNLV), northeastern base of

Yucca Mtn. (UNLV-C), Meiklejohn Mtn. (UNLV), Razorback Ridge(UNLV).

Lycium pallidum

var. oligospermum C. L. Hitche.

Steves Pass (JCB), Busted Butte(UNLV-C), Solitario Canyon(UNLV), canyon north of Wildcat Peak (UNLV).

Lycium shockleyi Gray

Northern Amargosa Valley(JCB), Steves Pass(UNLV), Black Marble Mtn. (UNLV), Crater Flat (UNLV-C), Busted Butte(UNLV-C), Forty-Mile Wash(UNLV), Solitario Canyon(UNLV-C), canyon north of Wildcat Peak(UNLV), Beatty Wash(UNLV), southern base of Yucca Mtn. (UNLV).

Nicotiana

Nicotiana trigonophylla Dunal in A. DC.

Desert tobacco

var. trigonophylla

Bare Mtn. (JCB), Chuckwalla Canyon(UNLV-C), Beatty Wash(UNLV), Solitario Canyon(UNLV), canyon north of Wildcat Peak(UNLV), Yucca Mtn. Ridge(UNLV), northeastern base of Yucca Mtn.(UNLV), Meiklejohn Mtn (UNLV).

Physalis

Physalis crassifolia Benth.

Canyon north of Wildcat Peak (UNLV-C).

Thickleaf ground-cherry

Solanum

1 Solanum americanum Miller

[=Solanum nodiflorum Jacq.]

Forty-Mile Wash(UNLV), Specie Spring(UNLV-C) .

Tamaricaceae Tamarisk Family

Tamarix

Tamarix ramosissima Ledeb.

Salt-cedar

[=T. pentandra Pallas]

Forty-Mile Wash (UNLV).

Urticaceae Nettle Family

Parietaria 
$D$ Parietaria hesper B.D. Hinton

[=Parietaria floridana Nutt.]

Chuckwalla Canyon(UNLV).

Verbenaceae Vervain Family

Verbena

Verbena bracteata Lag. \& Rodr.

Forty-Mile Wash (UNLV-C).

zygophyllaceae Caltrop Family

Larrea

Larrea tridentata (Sesse \& Moc ex DC.) Cov. Creosote-bush Crater Flat (JCB), Steves Pass (UNLV), Black Marble Mtn. (UNLV), Crater Flat (UNLV), Tarantula Canyon(UNLV), Tates Wash(UNLV-C), Yucca Mtn. (O\&C, UNLV), Busted Butte(UNLV), Forty-Mile Wash(UNLV), Beatty Wash(UNLV-C), Solitario Canyon(UNLV), canyon north of wildcat Peak (UNLV), southern base of Yucca Mtn. (UNLV), northeastern base of Yucca Mtn. (UNLV), Razorback Ridge(UNLV), Tates Wash (UNLV).

CLASS LILIATAE Monocotyledons

Agavaceae Agave Family

Yucca

Yucca brevifolia Engelm. in s. Wats.

Joshua-tree

[ $Y$. arborescens (Torr.) Trel.]

Crater Flat(JCB), Tates Wash(UNLV), Tarantula Canyon(UNLV-C), Chuckwalla Canyon(UNLV), Beatty Wash(UNLV), Yucca Mtn. Ridge(UNLV), Razorback Ridge (UNLV).

Amaryllidaceae Amaryllis Family

Allium

Allium atrorubens $S$. Wats.

$[=\mathrm{A}$. nevadense $\mathrm{s}$. Wats.]

Specie Spring(UNLV), Beatty Wash(UNLV-C), Meiklejohn Mtn. (UNLV-C).

Dichelostemma

Dichelostemma pulchellum (Salisb.) Heller

Bluedicks, desert-hyacinth

[= Hookera pulchella Salisb.;

Brodiaea pulchella (Salisb.) Greene;

B. capitata Benth.]

Tates Wash(JCB), Yucca Mtn. (O\&C), Forty-Mile Wash(UNLV-C), Beatty Wash (UNLV-C), Yucca Mtn. Ridge(UNLV), northeastern base of Yucca Mtn. (UNLV), Razorback Ridge (UNLV).

Cyperaceae Sedge Family

Carex

Carex praegracilis $W$. Boott 


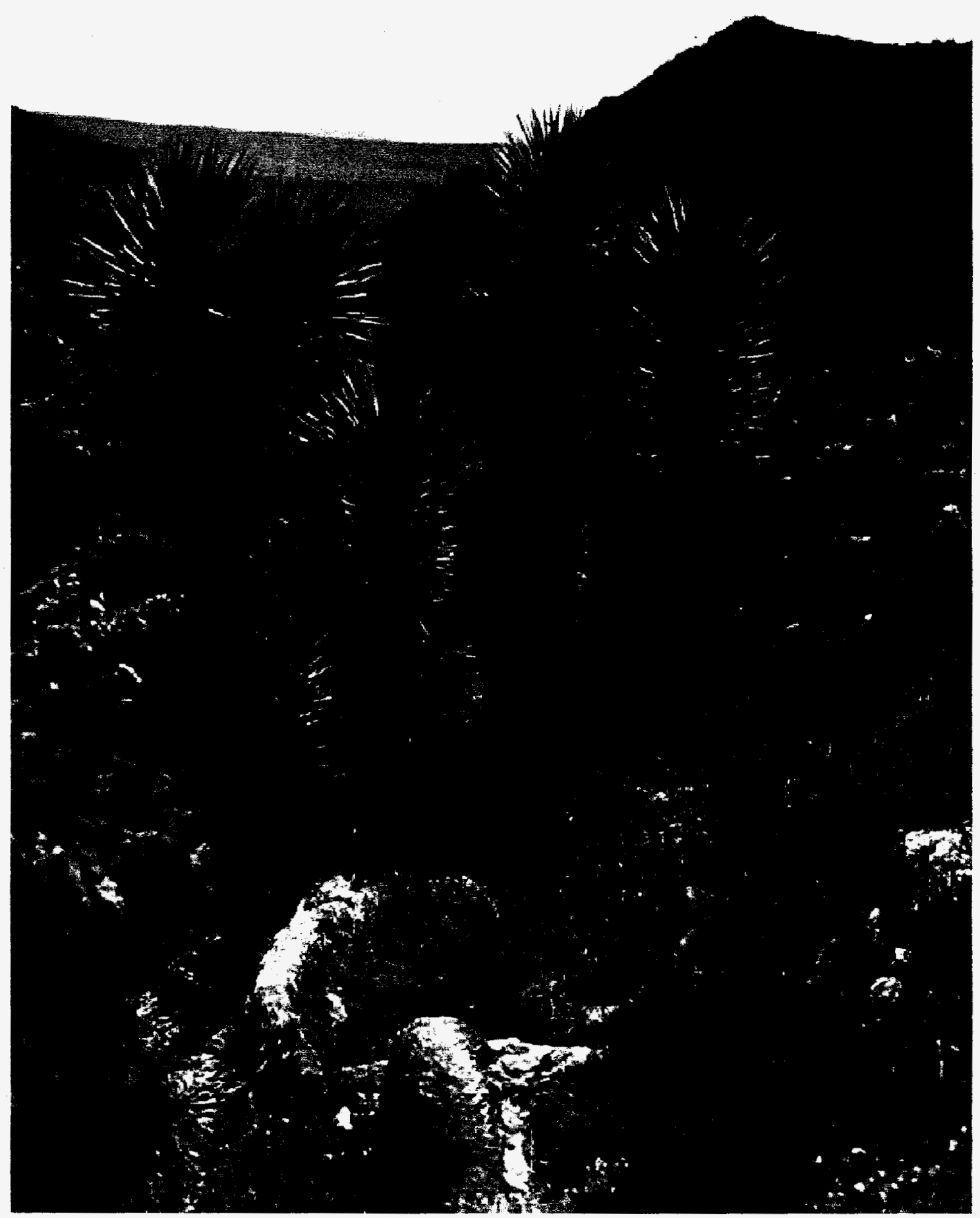

Figure 8. This small stand of Yucca brevifolia Engelm. in Wats. is located in Chuckwalla Canyon, Bare Mountain. Occasional plants or extensive stands occur throughout much of the study area. 
Specie Spring(UNLV-C), Forty-Mile Wash(UNLV-C) .

Juncaceae Rush Family

Juncus

Juncus balticus Willd.

Specie Spring (UNLV-C).

Liliaceae Lily Family

Calochortus

Calochortus Elexuosus $s$. Wats.

Crater Flat(JCB), Tarantula Canyon(UNLV), specie spring(UNLV), Chuckwalla Canyon(UNLV), Yucca Mtn. (O\&C, UNLV), Beatty Wash(UNLV), Solitario Canyon(UNLV), northeastern base of Yucca Mtn. (UNLV), Meiklejohn Mtn. (UNLV), Razorback Ridge(UNLV).

Poaceae Grass Family

Aristida

Aristida adscensionis $\mathrm{I}$.

Sixweeks threeawn

[=․․ oligantha authors]

Bare Mtn. (JCB).

Aristida purpurea Nutt.

Purple threeawn

$[=\underline{A}$. Eendleriana steudel;

A. glauca (Nees) Walp;

A. longiseta Steudel;

A. wrightii Nash]

Bare Mtn. (JCB), Black Marble Mtn. (UNLV), Tates Wash(UNLV), Busted Butte(UNLV), Chuckwalla Canyon(UNLV), Solitario Canyon(UNLV), canyon north of Wildcat Peak(UNLV-C), Razorback Ridge(UNLV).

Bromus

Bromus rubens $I$.

Red brome

[=B. laevipes ssp. rubens (L.) Husnot]

Black Marble Mtn. (UNLV), Chuckwalla Canyon(UNLV-C), Specie Spring(UNLV), Fluorspar Canyon(UNLV), Tates Wash(UNLV), Tarantula Canyon(UNLV), Yucca Mtn. (O\&C, UNLV), Busted Butte(UNLV), Forty-Mile Wash(UNLV), Beatty Wash(UNLV), Crater Flat (UNLV), southern base of Yucca Mtn. (UNLV), Yucca Mtn. Ridge(UNLV), northeastern base of Yucca Mtn. (UNLV), Meiklejohn Mtn. (UNLV), Razorback Ridge(UNLV), Tates Wash (UNLV).

Bromus tectorum L.

Chuckwalla Canyon(UNLV-C), Specie Spring(UNLV-C), Fluorspar Canyon(UNLV), Tates Wash(UNLV), Tarantula Canyon(UNLV), Yucca Mtn. (UNLV), Beatty Wash(UNLV-C), canyon north of Wildcat Spring(UNLV), Crater Flat(UNLV), Forty-Mile Wash(UNLV), Yucca Mtn. Ridge(UNLV). northeastern base of Yucca Mtn. (UNLV-C), Meiklejohn Mtn. (UNLV), Razorback Ridge (UNLV). 
Bromus trinii Desv.

Chilean chess

Bare Mtn. (JCB), Yucca Mtn. (UNLV-C), Busted Butte(UNLV-C), Solitario Canyon(UNLV-C), Beatty Wash(UNLV-C), Yucca Mtn. Ridge (UNLV-C), northeatern base of Yucca Mtn. (UNLV), Razorback Ridge (UNLV).

Elymus

Elymus elymoides (Raf.) Sweaey

Squirreltail

[ Sitanion elymoides Raf.;

Aegilops hystrix Nutt.;

S. hystrix (Nutt.) J.G. Sm.;

S. breviaristatum J.G. Sm.;

S. cinereum J.G. Sm.;

S. insulare J.G. Sm.]

Chuckwalla Canyon(UNLV), Tates Wash(UNLV), Crescent Cliff(UNLV), Tarantula Canyon(UNLV), Yucca Mtn. (UNLV-C), Beatty Wash (UNLV-C), Solitario Canyon(UNLV), canyon north of Wildcat Peak(UNLV), Yucca Mtn. Ridge (UNLV), northeastern base of Yucca Mtn. (UNLV), northeastern base of Yucca Mtn. (UNLV), Meiklejohn Mtn. (UNLV), Tates Wash (UNLV).

Elymus trachycaulus (link) Gould ex Shinn.

Slender wheatgrass

[= Agropyron trachycaulum (Link) Malte;

A. Iatigume (Scribn. \& Sm.) Rydb. ;

A. pauciflorum (Schwein) sensu A.S. Hitche.;

A. subsecundum (Link) A.S. Hitchc.;

A. tenerum Vasey;

A. violaceum var. andinum (Scribn. \& J.G. Small) Melderis]

Specie Spring (UNLV).

Elymus triticoides Buckley

[=Leymus triticoides (Buckley) Pilger]

Beatty Wash (UNLV)

Erioneuron

Erioneuron pulchellum (H.B.K.) Tateoka

Fluffgrass

[= Triodia pulchella H.B.K.;

Tridens pulchellus (H.B.K.) A.S. Hitchc.]

Crater Flat (UNLV), Chuckwalla Canyon(UNLV), Yucca Mtn. (UNLV), Busted Butte (UNLV), Beatty Wash(UNLV), Solitario Canyon(UNLV), canyon north of Wildcat Peak(UNLV), Beatty Wash(UNLV), southern base of Yucca Mtn. (UNLV).

Hilaria

Hilaria iamesii (Torr.) Benth.

Galleta, curlygrass

[= Pleuraphis jamesii Torr.]

Chuckwalla Canyon(UNLV), Tates Wash(UNLV), Crescent Cliff(UNLV-C), Tarantula Canyon(UNLV), Yucca Mtn. (O\&C, UNLV-C), Beatty Wash (UNLV), Solitario Canyon(UNLV), canyon north of Wildcat Peak (UNLV), Razorback Ridge (UNLV).

Hordeum

Hordeum murinum L.

Barley

ssp. leporinum (Link) Arcang. 
[= Hordeum leporinum Link]

Specie Spring(UNLV), Razorback Ridge(UNLV-C).

Muhlenbergia

Muhlenbergia porteri Scribn. ex Beal

Bush muhly

[ $=\underline{\mathrm{M}}$. texana Thurber]

Chuckwalla Canyon(UNLV), canyon north of Wildcat Peak(UNLV-C).

Poa

Poa bigelovii Vasey and Scribn.

Bigelow's bluegrass

Chuckwalla Canyon (UNLV-C).

Poa fendleriana (Steud.) Vasey

Muttongrass

[=Eragrostis fendleriana Steudel;

P. cusickii Vasey;

P. epilis Scribn;

P. Iongiligula Scribn. \& Williams;

P. eatonii S. Wats.;

P. scabriuscula Williams]

Chuckwalla Canyon(UNLV), Specie Spring(UNLV), Tates Wash(UNLV), Crescent Cliff(UNLV-C), Tarantula Canyon(UNLV), Yucca Mtn. (UNLV), Beatty Wash(UNLV), Yucca Mtn. Ridge(UNLV), northeastern base of Yucca Mtn. (UNLV), Meiklejohn Mtn. (UNLV), Razorback Ridge(UNLV), Tates Wash (UNLV).

Poa secunda Presl.

Sandberg's bluegrass

[=P. ampla Merr.;

D. brachyglossa Piper;

P. canbyi (Scribn.) Howell;

R. confusa Rydb.;

P. gracillima Vasey;

P. nevadensis Vasey;

R. Sandbergii Vasey;

P. Scabrella (Thurber) Benth.;

Atropis laevis var. rigida Beal]

Beatty Wash (UNLV-C), Razorback Ridge (UNLV).

Polypogon

Polypogon monspeliensis (L.) Desf.

Annual beardgrass

[ = Alopecurus monspeliensis L.]

Forty-Mile Wash(UNLV-C), Specie spring(UNLV-C).

Schi smus

Schismus arabicus Nees.

Mediterranean grass Crater Flat(UNLV), Busted Butte(UNLV-C), Solitario Canyon(UNLV), Yucca Mtn. (O\&C), Forty-Mile Wash (UNLV).

sporobolus

Sprobolus contractus A. Hitch.

Spike droopseed

Specie Spring (UNLV-C).

Sporobolus cryptandrus (Torr.) Gray

Sand dropseed 
[=Vilfa cryptandra Torr.]

Beatty Wash(UNLV-C), Meiklejohn Mtn. (UNLV).

stipa

Stipa arida M. E. Jones

Mormon needlegrass

[= S. mormonum Mez , ;

Achnatherum aridum (M.E. Jones) Barkworth]

North Bare Mtn. (JCB), canyon north of Wildcat Peak (UNLV-C), Meiklejohn Mtn. (UNLV-C).

Stipa $\times$ bloomeri Bolander

[=oryzopsis bloomeri (Bolander) Ricker]

Bloomer's ricegrass

Canyon north of Wildcat Peak(UNLV-C), Yucca Mtn. (O\&C).

Stipa comata Trin \& Rupr.

Needle-and-thread grass

[=Hesperostipa comata (Trin.\& Rupr.) Barkworth]

Crater Flat(UNLV), Tarantula Canyon(UNLV), Chuckwalla Canyon(UNLV), Yucca Mtn. (UNLV), Busted Butte(UNLV), Beatty Wash(UNLV), Solitario Canyon(UNLV), canyon north of Wildcat Peak(UNLV), Meiklejohn Mtn. (UNLVC), Razorback Ridge (UNLV).

Stipa coronata Thurb. in S. Wats.

Crested needlegrass

[= Achnatherum coronatum (Thurber) Barkworth]

Beatty Wash (UNLV)

Stipa hymenoides Roem. \& Schult.

Indian ricegrass

[=oryzopsis hymenoides (Roem. \& Schult.) Ricker;

Achnatherum hymenoides (Roem. \& Schult.) Barkworth]

Steves Pass(UNLV), Black Marble Mtn. (UNLV), Crater Flat (UNLV), Chuckwalla Canyon(UNLV), Tates Wash(UNLV), Tarantula Canyon(UNLV), Yucca Mtn. (O\&C, UNLV), Busted Butte(UNLV), Beatty Wash(UNLV), Solitario Canyon(UNLV), canyon north of Wildcat Peak (UNLV), northeastern base of Yucca Mtn. (UNLV), Razorback Ridge(UNLV), Tates Wash (UNLV).

Stipa speciosa Trin. \& Rupr.

Desert needlegrass

[= Achnatherum speciosum (Trin. \& Rupr.) Barkworth]

Crater Flat (UNLV), Chuckwalla Canyon(UNLV), Specie spring(UNLV), Fluorspar Canyon(UNLV), Yucca Mtn. (O\&C, UNLV-C), Tates Wash (UNLV-C), Tarantula Canyon(UNLV), Busted Butte(UNLV), Beatty Wash(UNLV), canyon north of Wildcat Peak(UNLV), Forty-Mile Wash(UNLV), southern base of Yucca Mtn. (UNLV), Yucca Mtn. Ridge(UNLV), northeastern base of Yucca Mtn. (UNLV), Meiklejohn Mtn. (UNLV), Razorback Ridge(UNLV), Tates Wash (UNLV).

Tridens

Tridens muticus (Torr.) Nash

Slim tridens

[= Tricuspis mutica Torr .;

Triodia mutica (Torr.) Scribn.]

Canyon north of Wildcat Peak (UNLV-C).

Triticum

1 Triticum aestivum L.

Wheat

Yucca Mtn. Ridge (UNLV-C). 
Vulpia

Dulpia bromoides (L.) S. F. Gray

[ = Eestuca bromoides L. ;

E. dertonensis (All.) Asch. \& Graebner]

Crescent Cliff(UNLV-C), Yucca Mtn. (O\&C), Beatty Wash(UNLV), northeastern base of Yucca Mtn. (UNLV-C), Razorback Ridge (UNLV).

Vulpia octoflora (Walt.) Rydb.

Sixweeks fescue

[=Festuca octoflora var. hirtella (Piper) Henrard]

Crescent Cliff(UNLV), Yucca Mtn. (UNLV), Busted Butte (UNLV-C), Beatty Wash(UNLV-C), Forty-Mile Wash(UNLV), southern base of Yucca Mtn. (UNLV), Yucca Mtn. Ridge (UNLV).

Typhaceae Cat-tail Family

Typha

Typha domingensis Pers.

Southern cattail Specie Spring (UNLV-C).

Iypha latifolia L.

Broad-Ieaved cattail

Forty-Mile Wash (UNLV), 


\section{SUMMARY}

Results of this survey, combined with those presented by other workers, indicate that the vascular flora of Yucca Mountain and vicinity is composed of 375 specific and infraspecific taxa. These taxa are representative of 179 genera and 54 families. Eleven of the species have not previously been reported as occurring in the area. The three families represented by the largest number of species are the sunflower or Asteraceae, with 73 species; the borage or Boraginaceae, 46 species; and the grass or Poaceae, 29 species.

No threatened or endangered taxon, currently listed under the Endangered Species Act, was recorded from the study area. Additional distributional data relative to those candidate species that do occur within the area has been incorporated in the annotated checklist. The first report of the presence of Gilia ripleyi on the east side of Bare Mountain is notable. 


\section{REFERENCES}

Beatley, J. C. 1976. Vascular plants of the Nevada Test Site and central-southern Nevada: ecologic and geographic distribution. National Technical Information Service (TID-26881).

Springfield, VA. $308 \mathrm{pp}$.

1977a. Endangered plant species of the Nevada Test Site, Ash Meadows and central-southern Nevada. U. S. Energy Research and Development Administration Report No. 000-230711 .

- 1977b. Threatened plant species of the Nevada Test Site, Ash Meadows and central-southern Nevada. U. S. Energy Research and Development Administration Report No. 000-230712 .

Cochrane, S. A. 1979. Status of endangered and threatened plant species on Nevada Test Site - A survey, parts 1 and 2 . Appendix C: collection records for the taxa considered. EG\&G Report No. EGG 1183-2356.

Collins, E., T. P. O'Farrell, and W. A. Rhoads 1981. Annotated bibliography for biological overview for the Nevada Nuclear Waste Storage Investigations, Nevada Test Site, Nye County, Nevada. EG\&G Report No. EGG 1183-2419.

Collins, E. and T. P. O'Farrell 1985. 1984 biotic studies of Yucca Mountain, Nevada Test Site, Nye County, Nevada. EG\&G Report No. 10282-2057.

Cornwall, H. R. 1972. Geology and mineral deposits of southern Nevada, Nye County, Nevada. Bull. 77, Nevada Bureau of Mines and Geology. Univ. of Nevada, Reno, NV.

Flora of North America Editorial Committee 1993. Flora of North America north of Mexico. Oxford Univ. Press, New York, N.Y. $475 \mathrm{pp}$.

Hickman, J. C. (ed.) 1993. The Jepson manual: higher plants of California. Univ. of California Press, Berkley, CA. 1400 pp. 
Kartesz, J. T. 1987. A flora of Nevada. Unpublished Ph.D. dissertation. Univ. of Nevada, Reno, NV. 1729 pp.

- 1994a. A ynonymized checklist of the vascular flora of the United States, Canada, and Greenland. Vol. 1Checklist. Timber Press, Portland, OR. $622 \mathrm{pp}$.

1994b. A synonymized checklist of the vascular flora of the United States, Canada, and Greenland. Vol. 2Thesaurus. Timber Press, Portland, OR. $816 \mathrm{pp}$.

Niles, W. E., P. J. Leary, J. S. Holland, and F. H. Landau. 1995. A floristic survey of Yucca Mountain and vicinity, Nye County, Nevada. Univ. of Nevada, Las Vegas, NV (prepared for the U.S. Dept. of Energy).

O'Farrell, T. P. and E. Collins 1983. 1982 biotic survey of Yucca Mountain, Nevada Test Site, Nye County, NV. EG\&G Report No. EGG 10282-2004.

\section{1983 biotic studies of Yucca Mountain,} Nevada Test Site, Nye County, NV. EG\&G Report No. EGG 10282-2031.

Rhoads, W. A. and M. P. Williams 1977. Status of endangered and threatened plant species on Nevada Test Site - a survey. Part 1: endangered species. EG\&G Report No. EGG 1183-2356.

Rhoads, W. A., S. A. Cochrane, and M. P. Williams 1978. Status of endangered and threatened plant species on Nevada Test Site a survey. Part 2: threatened species. EG\&G Report No. EGG $1183-2356$.

1978, Addendum to status of endangered and threatened plant species on Nevada Test Site - a survey. Parts 1 and 2. EG\&G Report No. EGG 1183-2356.

Welsh, S. L., N. D. Atwood, S. Goodrich, and L. C. Higgins (eds.). 1993. A Utah flora. Brigham Young Univ., Provo, Utah. 